\title{
Protocadherin- $\alpha$ Family Is Required for Serotonergic Projections to Appropriately Innervate Target Brain Areas
}

\author{
Shota Katori, ${ }^{1 \star}$ Shun Hamada, ${ }^{2 \star}$ Yukiko Noguchi, ${ }^{1}$ Emi Fukuda, ${ }^{1}$ Toshifumi Yamamoto, ${ }^{3}$ Hideko Yamamoto,${ }^{4}$ \\ Sonoko Hasegawa, ${ }^{1}$ and Takeshi Yagi ${ }^{1}$ \\ ${ }^{1}$ KOKORO-Biology Group, Laboratories for Integrated Biology, Graduate School of Frontier Biosciences, Osaka University, Osaka 565-0871, Japan, \\ ${ }^{2}$ Department of Nutrition and Health Sciences, Fukuoka Women's University, Fukuoka 813-8592, Japan, ${ }^{3}$ Laboratory of Molecular Recognition, Graduate \\ School of Arts and Sciences, Yokohama City University, Yokohama 230-0045, Japan, and ${ }^{4}$ Division of Psychobiology, Tokyo Institute of Psychiatry, Tokyo \\ 156-8585, Japan
}

Serotonergic axons from the raphe nuclei in the brainstem project to every region of the brain, where they make connections through their extensive terminal arborizations. This serotonergic innervation contributes to various normal behaviors and psychiatric disorders. The protocadherin- $\alpha$ (Pcdha) family of clustered protocadherins consists of 14 cadherin-related molecules generated from a single gene cluster. We found that the Pcdhas were strongly expressed in the serotonergic neurons. To elucidate their roles, we examined serotonergic fibers in a mouse mutant $\left(P c d h a^{\Delta C R / \Delta C R}\right)$ lacking the $P c d h a$ cytoplasmic region-encoding exons, which are common to the gene cluster. In the first week after birth, the distribution pattern of serotonergic fibers in Pcdha $a^{\Delta C R / \Delta C R}$ mice was similar to wild-type, but by 3 weeks of age, when the serotonergic axonal termini complete their arborizations, the distribution of the projections was abnormal. In some target regions, notably the globus pallidus and substantia nigra, the normally even distribution of serotonin axonal terminals was, in the mutants, dense at the periphery of each region, but sparse in the center. In the stratum lacunosum-moleculare of the hippocampus, the mutants showed denser serotonergic innervation than in wild-type, and in the dentate gyrus of the hippocampus and the caudateputamen, the innervation was sparser. Together, the abnormalities suggested that Pcdha proteins are important in the late-stage maturation of serotonergic projections. Further examination of alternatively spliced exons encoding the cytoplasmic tail showed that the A-type (but not the B-type) cytoplasmic tail was essential for the normal development of serotonergic projections.

\section{Introduction}

The largest family in the cadherin superfamily is the clustered protocadherins, which are mainly expressed in neurons and localized to axons and synapses (Obata et al., 1995; Kohmura et al., 1998; Phillips et al., 2003; Junghans et al., 2008; Yagi, 2008). All the clustered protocadherin genes encode type I transmembrane proteins with six extracellular cadherin domains ( $\mathrm{Wu}$ and Maniatis, 1999). The murine clustered protocadherins are further classified into three subfamilies, according to their position within the gene cluster: protocadherin- $\alpha$ (Pcdha, 14 genes), protocadherin- $\beta$ (Pcdhb, 22 genes), and protocadherin- $\gamma$ (Pcdhg, 22 genes) (Sugino et al., 2000; Wu et al., 2001). Interestingly, only a few, randomly selected genes of the Pcdha and Pcdhg clusters are ex-

\footnotetext{
Received Nov. 13, 2008; revised April 2, 2009; accepted June 8, 2009.

This work was supported in part by Grants-in-Aid from the Ministry of Education, Science, Sports, and Culture of Japan (T.Y.), a Grant-in-Aid for Scientific Research (S) (T.Y.), a Grant-in-Aid for Scientific Research on Priority Areas - Advanced Brain Science Project from the Ministry of Education, Culture, Sports, Science, and Technology, Japan (S.H.), and a grant from the Japan Foundation for Neuroscience and Mental Health (S.H.). We thank the members of the KOKORO Biology Laboratory for assistance and discussions, and M. Sanbo, N. Yamauchi, H. Masuda, and E. Naruto for technical assistance. We are grateful to Jun-ichi Miyazaki (Osaka University, Japan) for the CAG-Cre transgenic mice, and Masahiko Watanabe (Hokkaido University, Japan) for the anti-SERT antibody.

*S.K. and S.H. contributed equally to this work.

Correspondence should be addressed to Dr. Takeshi Yagi, KOKORO-Biology Group, Laboratories for Integrated Biology, Graduate School of Frontier Bioscience, Osaka University, 1-3, Yamadaoka, Suita 565-0871, Osaka, Japan. E-mail: yagi@fbs.osaka-u.ac.jp.

DOl:10.1523/JNEUROSCI.5478-08.2009

Copyright $\odot 2009$ Society for Neuroscience $\quad$ 0270-6474/09/299137-11\$15.00/0
}

pressed in individual Purkinje cells (Esumi et al., 2005; Kaneko et al., 2006). Thus, a given neuron expresses a diverse combination of individual clustered protocadherin molecules, consistent with the idea that differential expression of these genes may confer a unique identity on each neuron.

In humans, these clustered $P c d h$ genes are located on chromosome 5q31, a candidate locus for schizophrenia (SZ)- and bipolar disorder (BD)-related pathogenesis (Schwab et al., 1997; Lewis et al., 2003). Recently, a single nucleotide polymorphism (SNP) in the Pcdha gene locus was significantly linked to BD (Pedrosa et al., 2008). In addition, we recently reported that hypomorphic Pcdha mutant mice exhibit enhanced contextual fear conditioning and abnormal spatial learning (Fukuda et al., 2008). All of these findings are consistent with the 5q31-linked $P c d h$ locus being a diseasesusceptibility locus for certain psychiatric disorders.

Our current focus is on defining the brain regions in which the Pcdha genes are strongly expressed, and elucidating their roles in these regions. In a study of the olfactory sensory neurons (OSNs), which strongly express the Pcdha proteins, we found abnormal, ectopic olfactory neuronal projections in a Pcdha mutant $\left(P c d h a^{\Delta C R / \Delta C R}\right)$ mouse, which lacks the constant region (CR) exons encoding the common cytoplasmic tails of all Pcdha proteins (Hasegawa et al., 2008).

Here we focused on $P c d h$ expression in serotonergic neurons, and found by in situ hybridization analysis that Pcdha, but not $P c d h g$, is strongly expressed in the serotonergic neurons of the 
rostral raphe nuclei from fetal stages to adulthood. We examined the projections of the serotonergic neurons in the $P c d h a^{\Delta C R / \Delta C R}$ mice, because we had found abnormal projections in the mutant OSN axons (Hasegawa et al., 2008). In wild-type (WT) mice, serotonergic axons project to target regions throughout the brain; however, in the $P c d h a^{\Delta C R / \Delta C R}$ mice, these projections were incomplete with immature arborizations. Given the effect of the mutant cytoplasmic tail, we also tested the A and B isotypes of this region. Mice lacking the Pcdha A-type domain $\left(P c d h a^{\Delta A / \Delta A}\right)$, but not those lacking the Pcdha B-type domain $\left(P c d h a^{\Delta B / \Delta B}\right)$, showed much the same serotonergic fiber phenotypes as $P c d h a^{\Delta C R / \Delta C R}$ mice. Our data suggested that the Pcdha family plays essential roles in the maturation of serotonergic projections in the brain, and that the Pcdha A-type cytoplasmic tail is specifically important in this process.

\section{Materials and Methods}

Animal experiments. All the experimental procedures were in accordance with the Guide for the Care and Use of Laboratory Animals of the Science Council of Japan and were approved by the Animal Experiment Committee of Osaka University.

In situ hybridization histochemistry. We performed in situ hybridization histochemistry, as described previously with small modifications (Schaeren-Wiemers and Gerfin-Moser, 1993). To detect all of Pcdha transcripts (GenBank accession number D86916, nucleotides 25184559), all the Pcdhg transcripts (GenBank accession number NM033584, nucleotides 2485-4383), and the serotonin transporter (SERT) transcript (GenBank accession number NM_010484, nucleotides 235-1733), Pcdha-CR, Pcdhg-CR and SERT cRNA probes were synthesized using a digoxigenin-UTP RNA labeling Kit (Roche) according to the manufacturer's instructions. Mice were deeply anesthetized with diethyl ether, then the brain was removed, embedded in O.C.T. compound (Sakura), and quickly frozen in isopentane cooled with dry ice. Sections $(10-\mu \mathrm{m}-$ thick) were cut on a cryostat (Leica CM3050), thaw-mounted on slides (Matsunami), and air-dried. The sections were fixed in $4 \%$ paraformaldehyde (PFA) in $0.1 \mathrm{~m}$ phosphate buffer ( $\mathrm{PB}, \mathrm{pH} 7.3$ ) for $10 \mathrm{~min}$, washed three times in PBS, pH 7.4, acetylated for $10 \mathrm{~min}$ in $0.25 \%$ acetic anhydride in $0.1 \mathrm{~m}$ triethanolamine- $\mathrm{HCl}, \mathrm{pH} 8.0$, and washed three more times with PBS. Prehybridization was performed with hybridization buffer [ $50 \%$ formamide, $5 \times$ SSC $(20 \times$ SSC is $3 \mathrm{~m} \mathrm{NaCl}, 0.3 \mathrm{~m}$ sodium citrate, $\mathrm{pH} 7.0), 5 \times$ Denhardt's, $250 \mu \mathrm{g} / \mathrm{ml}$ yeast tRNA, $500 \mu \mathrm{g} / \mathrm{ml}$ salmon sperm DNA, and $0.2 \%$ protectRNA RNase inhibitor (Sigma)] for $30 \mathrm{~min}$. The digoxigenin-labeled cRNA probes were denatured for $5 \mathrm{~min}$ at $82^{\circ} \mathrm{C}$ and chilled on ice. Hybridization buffer containing $1 \mu \mathrm{g} / \mathrm{ml}$ of the cRNA probes was dropped onto the sections, and a coverslip was added. The slides were incubated for $12 \mathrm{~h}$ at $72^{\circ} \mathrm{C}$ in a humidified chamber $(50 \%$ formaldehyde, $5 \times \mathrm{SSC}$ ), washed four times with $0.2 \times \mathrm{SSC}$ at $72^{\circ} \mathrm{C}$, washed three times with TBS, pH 7.5 (100 mM Tris-HCl, pH 7.5, $100 \mathrm{~mm}$ $\mathrm{NaCl})$, and rinsed with TNT (0.05\% Tween 20 in TBS, pH 7.5). To detect the hybridized probes, the sections were blocked with blocking solution (2.5\% skim milk in TNT) for $30 \mathrm{~min}$, and then incubated with alkaline phosphatase (AP)-conjugated anti-digoxigenin antibody (1:1000 dilution, Roche) in the blocking solution for $1 \mathrm{~h}$. The sections were rinsed three times with TBS, pH 7.5, and the enzymatic activity was visualized with $0.2 \mathrm{~mm} 5$-bromo-4-chloro-3-indolyl-phosphate, $0.2 \mathrm{~mm}$ nitro blue tetrazolium in $100 \mathrm{~mm}$ Tris- $\mathrm{HCl}, \mathrm{pH}$ 9.5, $100 \mathrm{~mm} \mathrm{NaCl}, 20 \mathrm{~mm} \mathrm{MgCl}_{2}$, in the dark, until the signal reached a satisfactory intensity.

We also carried double fluorescent in situ hybridization. A fluoresceinlabeled SERT cRNA probe was synthesized with a fluoresein-UTP RNA labeling Kit (Roche). Both digoxigenin-labeled Pcdha-CR and fluorescein-labeled SERT cRNA probes were hybridized to sections, and washed (see above). After rinsed with TNT, the sections were blocked with the blocking solution, and then incubated with anti-digoxigenin peroxidase (POD)-labeled anti-digoxigenin Fab fragments (1:3000 dilution; Roche) in the blocking solution for $3 \mathrm{~h}$, and washed three times with TNT. The signal of $P c d h a$ transcript was amplified and detected by TSA Plus Cyanine 3 system (PerkinElmer). The sections were washed three times with TNT, and rinsed with TBS, $\mathrm{pH}$ 7.5. For the inactivation of the $\mathrm{POD}$, the sections were incubated in $2 \% \mathrm{H}_{2} \mathrm{O}_{2}$ in TBS, $\mathrm{pH} 7.5$ for $15 \mathrm{~min}$ twice, and washed with TBS, pH 7.5 three times. The sections were incubated with POD-labeled anti-digoxigenin Fab fragments (1:3000 dilution, Roche) in the blocking solution for $3 \mathrm{~h}$, and washed with TNT three times, and washed with TBS, pH 7.5. The signal of SERT transcript was amplified by TSA Plus DNP (HRP) System (Perkin-Elmer), and washed with TNT three times. The sections were incubated with antidinitrophenyl (DNP)-Alexa 488 (1:1000 dilution, Invitrogen) in the blocking solution for $1 \mathrm{~h}$, washed with TNT three times and the signal of SERT transcript was detected.

Generation of Pcdha mutant mice. The CR exons of the Pcdha gene cluster generate two alternative carboxy-terminal regions: A and B (see Fig. $2 A, B)$. The type A-deleted ( $\triangle A n e o$ ), type B-deleted $(\Delta B)$ (see Fig. $2 E$ ) and CR-deleted $(\Delta C R)$ (see Fig. $2 C$ ) alleles were produced as described previously (Fukuda et al., 2008; Hasegawa et al., 2008). Since $P c d h a^{\Delta A n e o / \Delta A n e o}$ brains express considerably smaller amount of truncated Pcdha proteins probably because of promoter interference of $P G K$ $n e o$, we generated a new genetically modified allele, $\Delta A$ allele, in which a floxed $P G K-n e o$ in $\triangle A n e o$ allele was removed by crossing the $P c d h a^{+/ \Delta A n e o}$ mice with a line expressing Cre recombinase under the control of the CAG promoter (CAG-Cre) (Kawamoto et al., 2000) (supplemental Fig. $1 \mathrm{~A}$, available at www.jneurosci.org as supplemental material). The genotypes of the $P c d h a^{+/ \Delta A}$ and $P c d h a^{\Delta A / \Delta A}$ mice were confirmed by PCR using primers NA-F (5'-GGTGAGTTGCCAGACAAATTC- $\left.3^{\prime}\right)$ and mhl-2R (5'-GCCCTGCAAATATCATCAAT-3') (supplemental Fig. $1 B$, available at www.jneurosci.org as supplemental material). All of the gene-targeted mice used in this study were backcrossed to $\mathrm{C} 57 \mathrm{BL} / 6$ mice $>8$ times.

Immunohistochemistry. Male mice were deeply anesthetized with diethyl ether and perfused transcardially with PBS followed by 4\% PFA in $0.1 \mathrm{M}$ PB. After perfusion fixation, the brain was rapidly removed and immersed in the same fixative for $8 \mathrm{~h}$. The brain was then immersed in $20 \%$ sucrose in $0.1 \mathrm{M} \mathrm{PB}$ overnight and frozen in O.C.T. compound with isopentane cooled by dry ice. Coronal and sagittal sections were cut on a cryostat, thaw-mounted on slides, and air-dried as described above. The sections were washed with PBS, blocked for $1 \mathrm{~h}$ with PBST $(0.2 \%$ Triton X-100 in PBS) containing 20\% blocking reagent and 5\% normal goat serum, and incubated with a rabbit polyclonal anti-SERT antibody (HTT-N77, a generous gift from Dr. Masahiko Watanabe, Hokkaido University, Japan) in PBST containing 5\% blocking reagent for $12 \mathrm{~h}$ at $4^{\circ} \mathrm{C}$. The sections were rinsed with PBST and incubated with biotinylated anti-rabbit IgG antibody (1:500 dilution; Vector Laboratories) in PBST containing $5 \%$ blocking reagent for $2 \mathrm{~h}$. The sections were washed with PBS, incubated with avidin-biotin complex (1:100 dilution; Vector Laboratories) in PBS for $1 \mathrm{~h}$, and washed again with PBS. Finally, the sections were rinsed with $0.02 \%$ diaminobenzidine tetrachloride (DAB) in PBS, and reacted with $0.02 \% \mathrm{DAB}$ and $0.002 \% \mathrm{H}_{2} \mathrm{O}_{2}$ in PBS for 5-8 min.

Cytochrome oxidase histochemistry. Mice were deeply anesthetized with diethyl ether and perfused with PBS followed by $4 \%$ PFA in $0.1 \mathrm{M} \mathrm{PB}$. After the perfusion, cerebral hemispheres were removed, flattened between two glass slides, and then immersed the same fixative for $2 \mathrm{~h}$. The flattened tissues were immersed in $0.1 \mathrm{M} \mathrm{PB}$ containing $25 \%$ sucrose overnight for cryoprotection. Sections $(50 \mu \mathrm{m})$ were cut on a freezing microtome and were rinsed with $0.1 \mathrm{M} \mathrm{PB}$. The cytochrome oxidase activity was visualized with the solution containing $0.05 \%$ cytochrome $\mathrm{C}$, $0.05 \% \mathrm{DAB}$ and $4 \%$ sucrose for $1 \mathrm{~h}$ at $37^{\circ} \mathrm{C}$. The sections were then rinsed with $0.1 \mathrm{M} \mathrm{PB}$ and mounted onto glass slides and enclosed in $0.05 \mathrm{M} \mathrm{PB}$ containing $50 \%$ glycerol.

Illustrations and analysis of serotonergic fiber distribution and morphology. Sections stained by in situ hybridization histochemistry and immunohistochemistry were examined with an Olympus microscope (BX51), and photographed with a CCD camera (Olympus DP-50). The brightness and contrast were adjusted in Adobe Photoshop (Adobe Systems). To improve the visibility of the SERTimmunopositive (i.p.) fibers, the absolute values of the difference between the 8-bit color tissue images and their nontissue background images were mathematically calculated with Photoshop. The background-removed images were converted to 8-bit grayscale im- 
ages. To extract SERT-i.p. fibers specifically, we converted the grayscale images to binary images by setting a threshold for a brightness value. The density of SERT-i.p. fibers in the dorsal parts of the hippocampus in three parasagittal sections $(0.7,0.8$, and $0.9 \mathrm{~mm}$ from the midsagittal plane) was automatically measured in the region of interest (see Fig. $5 E$ ) per animal by NIH ImageJ 1.36b.

Quantification of SERT-positive cells. Serial sagittal sections $(10 \mu \mathrm{m}$ thick) were prepared from male mouse brains at postnatal day (P) 21 $\left(n=4 \mathrm{WT} ; n=4 P c d h a^{\Delta C R / \Delta C R}\right)$. Semiserial sections (one of each set of four) were hybridized with the SERT cRNA probe, and signals were detected by in situ hybridization histochemistry. In the rostral raphe nuclei from the midline $(0 \mu \mathrm{m})$ and laterally (bilateral; $720 \mu \mathrm{m}$ from the midline), only SERT transcript-positive cells whose nucleus could be discriminated were counted.

Statistical analysis. We used StatView software (SAS Institute) for statistical analyses. Statistical analyses between multiple mouse lines were done with one-factor ANOVA and Scheffé's $F$ test. Statistical analyses between two mouse lines were done with the Mann-Whitney $U$ test. Overall survivals of WT and mutant mice were examined with the Kaplan-Meier methods, and differences were done with logrank test. Values in graphs are expressed as the mean \pm SD.

Production of Pcdha-CR monoclonal antibodies. To generate specific monoclonal antibodies against all Pcdha proteins and a Pcdhac2 protein, we used amino acid sequences of the $\mathrm{CR}$ that is common to both the Aand B-types (PcdhaAB) and the specific extracellular domain of the Pcdhac2 (Pcdhac2EC2-3), respectively. The regions were amplified with primer pairs (5'-CCCCGGCAGCCCAACCCT-3' and 5'-GGGACCGGACTGTTTGGG-3' for PcdhaAB) or (5'-CCGGAATTCCCGCGGCCGGATTATCAGCTT-3' and 5'-CCGCTCGAGCACCTCTGGAGCGTTGTCATT-3' for Pcdhac2EC2-3) and cloned into the BamHI and EcoRI sites, or the EcoRI and XhoI sites of pGEX6P-1 (GE Healthcare), and the vectors were introduced into Escherichia coli (DH5 $\alpha)$. The glutathione $S$-transferase (GST)-PcdhaAB fusion protein and the GSTPcdhac2EC2-3 fusion protein were extracted from the E. coli by a Glutathione Sepharose 4 Fast Flow (GE Healthcare) column, and the PcdhaAB protein were obtained by cleavage with PreScission Protease (GE Healthcare). Emulsions of the PcdhaAB and GST-Pcdhac2EC2-3 proteins by TiterMAX GOLD adjuvant (CytRx Corporation) were injected four times intraperitoneally into $P c d h a^{\Delta C R / \Delta C R}$ female mice (Hasegawa et al., 2008) and $P c d h a^{\operatorname{del}(11-c 2) / \operatorname{del}(11-c 2)}$ female mice, in which Pcdha11-Pcdhac2 genes were deleted (Noguchi Y, Hirabayashi T, Katori S, Kawamura Y, Sanbo M, Hirabayashi M, Kiyonari H, Nakao K, Uchimura A, Yagi T, unpublished data), respectively. After the one or three booster immunizations, the spleens were extirpated and dispersed by passing it through a mesh (stainless steel, pore size: 100 $\mu \mathrm{m})$. The spleen cells were fused with P3UI mouse myeloma cells at a 5:1 ratio by polyethylene glycol. The fused cells were plated in ClonaCell-HY (StemCell Technologies). After $10 \mathrm{~d}$, the colonies were individually collected into 96-well plates and cultured in $10 \%$ fetal bovine serum-10\% BM Condimed (Roche)-RPMI medium (FBRM) containing hypoxanthine and thymidine. Immunopositive supernatant against the PcdhaAB and Pcdhac2EC2-3 protein was screened with ELISA and immunoblotting, and positive colonies were selected. Hybridomas (colony name: $4 \mathrm{~F} 8$ ) producing an antibody against the PcdhaAB protein were injected into nude mice, and their ascitic fluid was used as an anti-Pcdha-CR antibody. Hybridomas (colony name: $8 \mathrm{~B} 6$ ) producing an antibody against the Pcdhac2EC2-3 protein were cultured in FBRM, and the supernatant was used as an anti-Pcdha-c2 antibody. The specificity of these antibodies was confirmed with immunoblotting for brain lysate.

Immunoblotting. Whole P21 brains were dissected and homogenized in $50 \mathrm{~mm}$ Tris-HCl, pH 7.5, $2 \mathrm{~mm}$ EDTA, $2 \%$ SDS, $10 \mu \mathrm{g} / \mathrm{ml}$ pepstatin, and $10 \mu \mathrm{g} / \mathrm{ml}$ leupeptin. The homogenate was spun at $20,000 \times g$ at $4^{\circ} \mathrm{C}$ for $30 \mathrm{~min}$. An equal volume of SDS sample buffer (60 mM Tris-HCl, $\mathrm{pH} 6.7,2 \%$ v/v 2-mercaptoethanol, and 5\% glycerol) was added to the lysates for SDSPAGE followed by immunoblotting. The anti-Pcdha-CR and Pcdha-c2 (8B6) antibodies were used at 1:100 and 1:2 dilutions, respectively.

Reverse transcription-PCR. Total RNAs from mouse whole brains at P21 were extracted with TRIzol reagent (Invitrogen), and cDNAs were synthesized from the total RNAs with oligo-dT primers and Superscript
III (Invitrogen) reverse transcriptase, following the manufacturer's protocol. To detect Pcdha A-type and B-type transcripts, the cDNAs were amplified by PCR with forward primer CP1-F4 (5'-CGCTACTCTGCCTCGCTAA-3') and reverse primer CP3-R2 (5'-TGCAATCCTGCAGAGCTGAAG- $3^{\prime}$ ).

Measurement of monoamines by high performance liquid chromatography (HPLC). The amounts of monoamines and their metabolites were measured using HPLC with electrochemical detection (described by Fukuda et al., 2008). Mice were killed by decapitation at 10 weeks of age, and the brain regions were rapidly dissected out and frozen at $-80^{\circ} \mathrm{C}$, until assayed. Each sample of frozen brain tissue was homogenized by ultrasonic irradiation in $250 \mu \mathrm{l}$ of $0.2 \mathrm{M}$ perchloric acid containing isoproterenol as an internal standard. The homogenates were placed on ice for $30 \mathrm{~min}$ and spun at $20,000 \times g$ for $15 \mathrm{~min}$ at $4^{\circ} \mathrm{C}$. The supernatants were filtered through a syringe filter unit (DISMIC-3; Advantec), their $\mathrm{pH}$ was adjusted to 3.0 with $1 \mathrm{~m}$ sodium acetate, and they were then injected into an HPLC system equipped with an ODS column (Eicompak SC3-ODS; $3 \times$ $100 \mathrm{~mm}$; Eicom) and an electrochemical detector (EDC-100; Eicom) with the potential set at $+750 \mathrm{mV}$. The mobile phase was $0.1 \mathrm{M}$ citric acid and $0.1 \mathrm{M}$ sodium acetate, $\mathrm{pH} 3.5$, containing sodium-1-octansulfonate (190 mg/L), EDTA-2Na (5 mg/L), and 17\% methanol. The flow rate was set at $0.25 \mathrm{ml} / \mathrm{min}$. The protein content was measured using the Bradford protein assay solution (Bio-Rad) after the precipitates were solubilized with $0.1 \mathrm{M} \mathrm{NaOH}$.

\section{Results}

\section{Serotonergic neurons intensely express Pcdhas in the mouse brain}

To investigate where Pcdha transcripts are most strongly expressed in the brain, we examined the expression pattern of Pcdha transcripts by in situ hybridization histochemistry, using a Pcdha-CR cRNA probe to detect all the Pcdha transcripts (Esumi et al., 2005; Hasegawa et al., 2008). As has been reported, strong signals for Pcdha were detected in the olfactory bulb, neocortex, hippocampus, and cerebellum (in the Purkinje cells) (Fig. 1A) (Carroll et al., 2001; Morishita et al., 2004; Esumi et al., 2005; Hasegawa et al., 2008). In addition to these regions, we found that the rostral raphe nuclei were among the strongest expressors of Pcdha in the brain (Fig. 1A), with a peak between (E) 14.5 and P14 (Fig. $1 C-F$ ), and expression was maintained through adulthood (Fig. $1 G$ ). Serotonergic neurons in the raphe nuclei specifically express SERT. The cells of the rostral raphe nuclei that were positive for Pcdha transcript also stained positive for SERT transcript on the same section (Fig. $1 \mathrm{H}-\mathrm{J}$ ), indicating that the serotonergic neurons of the rostral raphe nuclei specifically expressed high levels of Pcdha transcripts.

Since some Pcdha proteins form a molecular complex with Pcdhg proteins (Murata et al., 2004), we compared the overall expression pattern of the Pcdha transcripts with that of Pcdhg. As with $P c d h a$, we used a CR probe, $P c d h g-C R$ cRNA, to detect all of the $P c d h g$ transcripts. Although many brain regions that strongly expressed $P c d h a$ transcripts also showed intense signals for $P c d h g$ (Fig. $1 A, B$ ), the rostral raphe nuclei showed much weaker $P c d h g$ signals. Thus, serotonin neurons in the raphe nuclei predominantly expressed Pcdha transcripts. We therefore examined the serotonergic system of the Pcdha mutant mouse brain in detail.

\section{Distribution of serotonergic fibers and somata in $P c d h a^{\Delta C R / \Delta C R}$ mice at P21}

Recently, we demonstrated that the axonal projections of the OSNs to the olfactory glomeruli are disturbed in $P c d h a^{\Delta C R / \Delta C R}$ mice, which lack the CR exons of Pcdha (Fig. 2C). In $P c d h a^{\Delta C R /}$ $\triangle C R$ brain lysates, Pcdha proteins were not detected by an antiPcdha-CR antibody against the common amino acids of the A and B CR types (Fig. 2 F), but CR-deleted Pcdha proteins were 
faintly detected by an anti-Pcdha-c2 antibody against the extracellular region of Pcdha-c2 (Fig. 2G). Therefore, we began our loss-of-function analyses of Pcdha in serotonergic neurons using the $P c d h a^{\Delta C R / \triangle C R}$ mice. To identify the serotonergic fibers, we immunolabeled brain sections with an anti-SERT antibody. There were no obvious cytoarchitectural abnormalities in the regions we examined (data not shown).

\section{Olfactory bulb}

In the olfactory bulb, the serotonergic fibers of WT mice were abundant in all layers of the bulb; in comparison, in the $P c d h a^{\Delta C R / \triangle C R}$ mice, there were fewer serotonergic fibers in the layers encompassed by and including the external and internal plexiform layers, and there were more than normal in the granule cell layer (Fig. $3 A, B)$.

\section{Cerebral cortex}

In the cingulate cortex (the medial part of the prefrontal cortex), the density of the serotonergic fibers in the $P c d h a^{\Delta C R / \Delta C R}$ mice was lower throughout, compared with WT mice (Fig. 3C,D). In the rostral region of the primary motor cortex, the serotonergic fibers of WT mice were abundant from layers I to VI (Fig. 3E), with a slightly higher density in layers I and IV (Fig. 3E). In contrast, in the $P c d h a^{\Delta C R / \triangle C R}$ mice, layer I was more densely innervated by serotonergic fibers (Fig. 3E,F), and short, clumped fibers were frequently observed in layer II/III of only the most rostral part of the $P c d h a^{\Delta C R / \triangle C R}$ primary motor cortex (Fig. 3F, arrowheads, bottom). In the entorhinal cortex, the density of the serotonergic fibers in the $P c d h a^{\Delta C R / \Delta C R}$ mice was dramatically greater than in WT mice (Fig. 3G,H).

\section{Basal ganglia}

In WT mice, the density of serotonergic fibers was moderate at P21 in the caudate-putamen and high in the globus pallidus (Fig. 4A). In $P c d h a^{\Delta C R / \Delta C R}$ mice, the density of serotonergic fibers dramatically decreased in the caudateputamen and increased in the globus pallidus, compared with WT mice (Fig. $4 A, B)$. Interestingly, the increase of serotonergic fibers in the $P c d h a^{\triangle C R / \triangle C R}$ globus pallidus was prominent only in the peripheral region (Fig. $4 B$, arrows). Similarly, the density of serotonergic fibers in the $P c d h a^{\Delta C R / \Delta C R}$ mice obviously increased in the peripheral region of the substantia nigra (Fig. $4 C, D)$. In contrast to the peripheral regions, the central regions of the globus pallidus and substantia nigra of the $P c d h a^{\Delta C R / \triangle C R}$ mice were more sparsely innervated by serotonergic fibers compared with WT (Fig. $4 B, D$, asterisks).
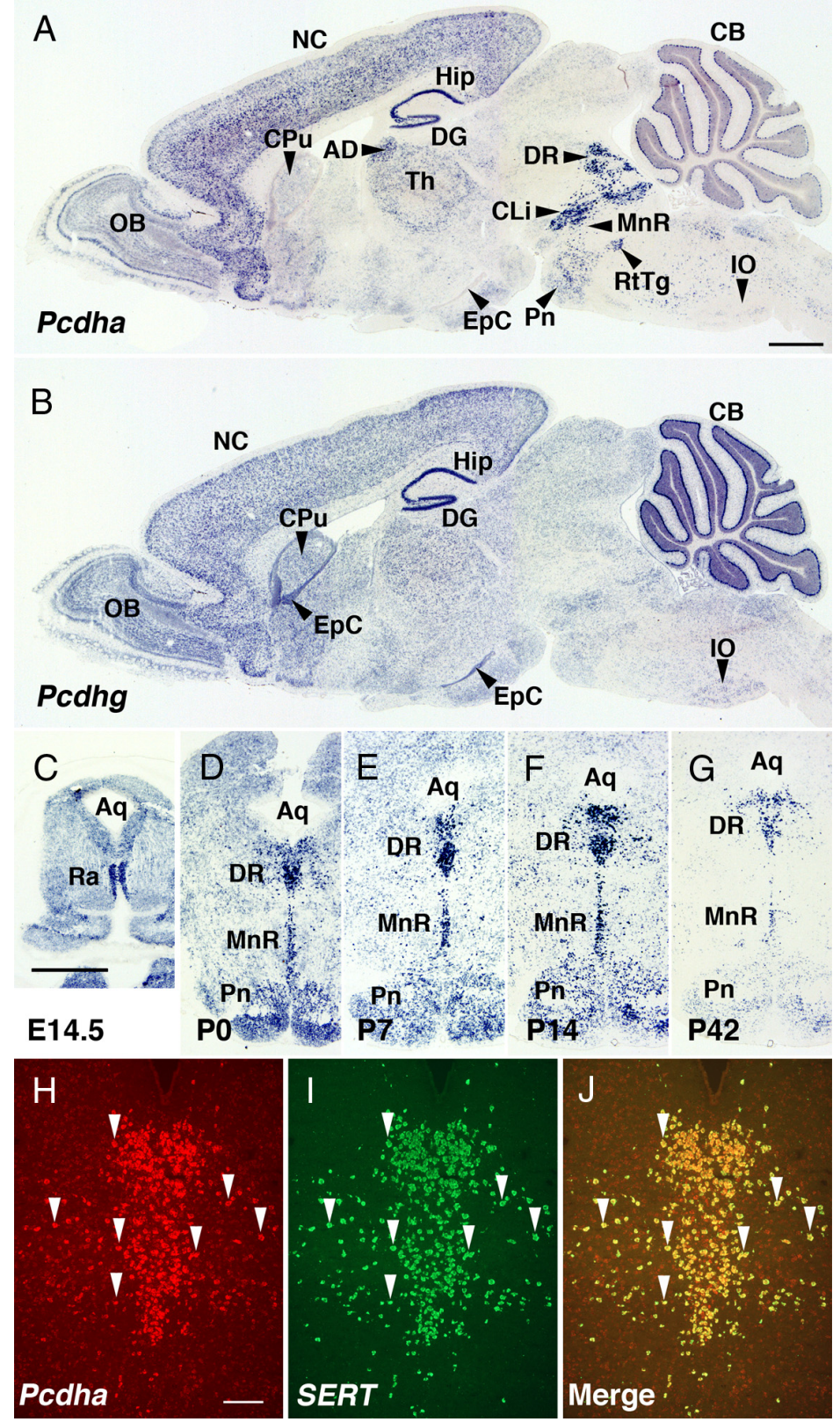

Figure 1. Serotonergic neurons strongly express $P$ cdhas in the mouse brain. $A, B$, The expression patterns of $P$ cdhas $(\boldsymbol{A})$ and $P c d h g s(B)$ in adjacent sagittal sections of $P 14$ mice. $P(d h a s$ and $P(d h g s$ were strongly expressed in various regions, including the olfactory bulb (OB), neocortex (NC), hippocampus (Hip), dentate gyrus (DG), thalamus (Th), and cerebellum (CB). Pcdhas were very strongly expressed in the rostral raphe nuclei (DR, dorsal raphe nuclei; MnR, median raphe nucleus; $\mathrm{CLi}$, caudal linear nucleus raphe). $P$ cdhgs were expressed in the caudate-putamen (CPu), ependymal cells (EpC), and inferior olive (I0). AD, Anterodorsal thalamic nucleus; $P$ n, pontine nuclei; RtTg, reticulotegmental nucleus of the pons. $C-G$, Coronal sections showing expression of Pcdhas in the rostral raphe nuclei at embryonic day (E) 14.5 (C), P0 (D), P7 (E), P14 (F), and P42 (G). The expression levels of Pcdhas were highest between E14.5 and P14. Aq, Aqueduct; Ra, raphe nuclei. $\boldsymbol{H}-J$, Double fluorescent in situ hybridization with Pcdha-CR $(\boldsymbol{H}$, arrowheads) and SERT probes ( $\boldsymbol{I}$, arrowheads) in the DR at P21 showed that SERT-positive cells were consistent with PcdhaCR-positive cells (J, arrowheads). Scale bars: $(\boldsymbol{A}-\mathbf{G}), 1 \mathrm{~mm} ;(\boldsymbol{H}-J), 200 \mu \mathrm{m}$.

\section{Thalamus}

In WT mice serotonergic fibers were distributed almost uniformly in the dorsal lateral geniculate nucleus and medial geniculate nucleus at P21 (Figs. $3 G, 4 E$ ), whereas in the $P c d h a^{\Delta C R / \Delta C R}$ mice serotonergic fibers were accumulated around these nuclei and sparse in the central regions of these nuclei (Figs. $3 H, 4 F$ ).

\section{Hippocampus}

In WT mice, serotonergic fibers were found throughout the hippocampal region. As has been reported (Lidov et al., 1980; Lidov 

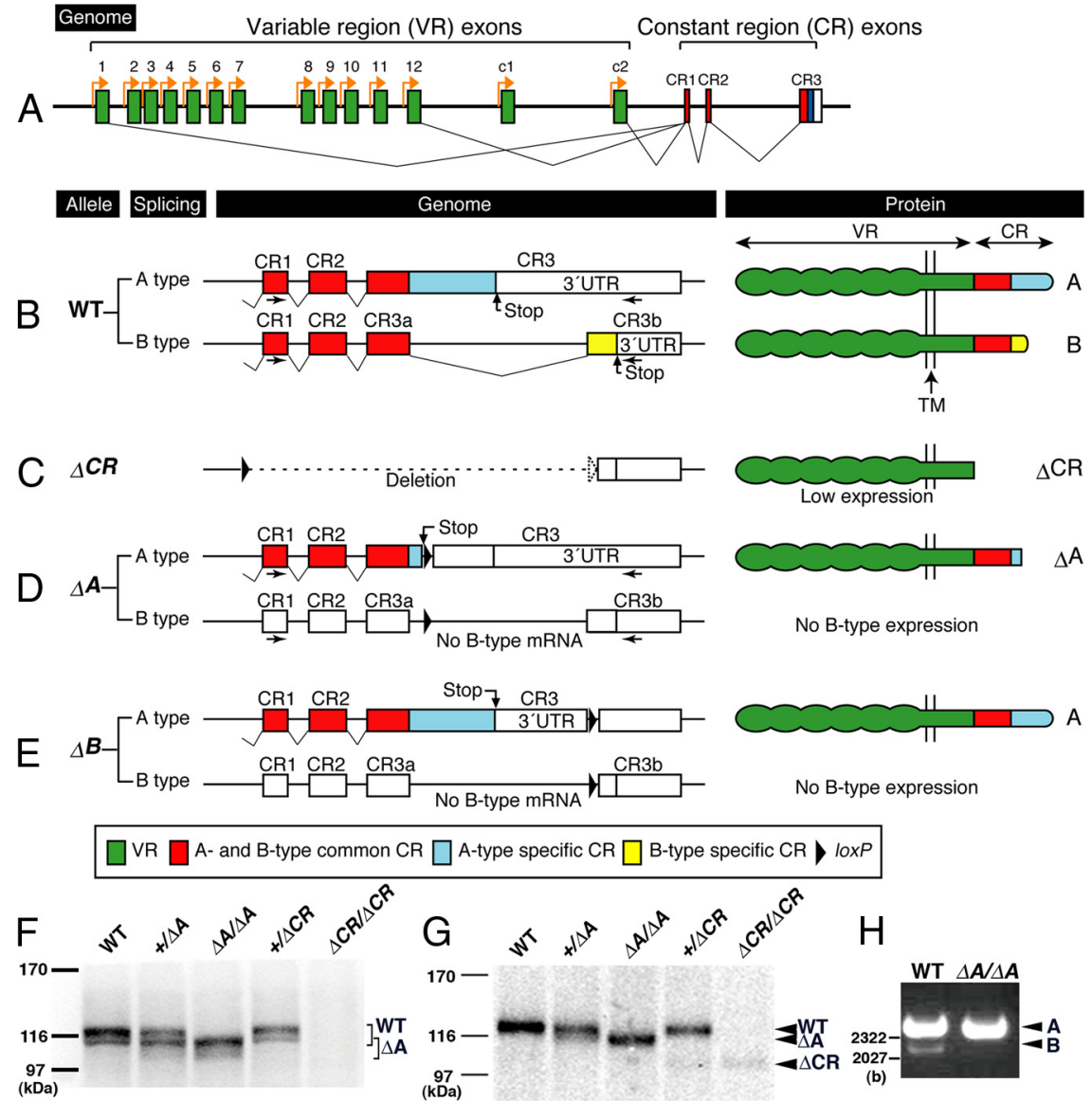

Figure 2. Summary of $P$ cdha mutant alleles and their products. $\boldsymbol{A}, P$ cdha genes consist of variable region (VR) exons (1-12, $\mathrm{C} 1$ and $C 2$; green) and CR exons (CR1-CR3). The individual VR exons are transcribed from their own promoter (orange arrows). $A$ $P c d h a$ transcript is produced from one of the variable region exons and a set of CR exons by splicing. $\boldsymbol{B}$, In the wild-type (WT) allele, alternative splicing of the $C R$ exons of $P$ cdha genes produces $A$ - and B-type variants ( $B$, left). The CR exons consist of an $A$ - and B-common coding region (red), an A-specific coding region (blue), a B-specific coding region (yellow), and a 3'UTR (white). Pcdha proteins are single-pass membrane proteins. The extracellular, transmembrane (TM) and cytoplasmic domains are encoded in the VRexons, and their cytoplasmic domain is encoded in the CR exons ( $B$, right). $C$, In the $\Delta$ (R allele, the coding region of the CR exons was deleted ( $\boldsymbol{C}$, left). From the $\Delta C R$ allele, $(R$-deleted Pcdha proteins $(\Delta C R)$ were faintly expressed $(\boldsymbol{C}$, right; $\boldsymbol{F}, \boldsymbol{G}) . \boldsymbol{D}, \operatorname{In}$ the $\Delta A$ allele, a termination codon and a loxP site were inserted into the $A$-specific coding region ( $\boldsymbol{D}$, left). From the $\Delta A$ allele, truncated proteins $(\Delta A)$ were expressed ( $\boldsymbol{D}$, right). $\boldsymbol{E}$, In the $\Delta B$ allele, a loxP site was inserted into the B-specific coding region ( $\boldsymbol{E}$, left). From the $\Delta B$ allele, $A$-type proteins were normally expressed, but B-type proteins were not ( $\boldsymbol{E}$, right). The recombination constructs for $\Delta C R, \Delta A$, and $\Delta B$ alleles were described in detail previously (Fukuda et al., 2008; Hasegawa et al., 2008) (supplemental Fig. $1 A$, available at www.jneurosci.org as supplemental material). $\boldsymbol{F}$, Immunoblotting analysis of brain lysates with a monoclonal antiPcdha-CR antibody. In WT, $P c d h a^{+/ \Delta A}$ and $P c d h a^{+/ \Delta C R}$ mice, bands of $\sim 116 \mathrm{kDa}$ were detected (indicated by WT), but in the $P c d h a^{\Delta A / \Delta A}$ and $P c d h a^{+/ \Delta A}$ mice, bands representing truncated $P c d$ has was detected (indicated by $\left.\Delta \mathrm{A}\right)$. No $(R-p o s i t i v e$ band was detected in the $P c d h a^{\Delta C R / \Delta C R}$ mice. G, Immunoblotting analysis of brain lysates with a monoclonal anti-Pcdha-c2 antibody, which was raised against the extracellular region of $P c d h a-c 2$ protein. In WT, $P c d h a^{+/ \Delta A}$ and $P c d h a^{+/ \Delta C R}$ mice, a band representing a $P c d h a-c 2$ protein was detected (indicated by WT), but in the $P c d h a^{\Delta A / \Delta A}$ and $P c d h a^{+/ \Delta A}$ mice, a band representing a $\Delta \mathrm{A}$ protein was detected (indicated by $\Delta \mathrm{A}$ ). $\mathrm{A}$ band representing a $\Delta C R$ protein was faintly detected in the $P c d h a^{+/ \Delta C R}$ and $P c d h a^{\Delta C R / \Delta C R}$ mice (indicated by $\Delta C R$ ). $\boldsymbol{H}$, Reverse transcript-PCR analysis for the total RNA of whole brains with a primer pair for the CR1 and CR3b exons (arrows in $\boldsymbol{B}, \boldsymbol{D}$ ). In WT mice, A-type (upper) and B-type (lower) bands were detected. In $P c d h a^{\Delta A / \Delta A}$ mice, no B-type transcript was transcribed.

and Molliver, 1982), the density of the serotonergic fibers in the WT hippocampus was relatively higher in the stratum lacunosum-moleculare and stratum radiatum, and relatively lower in the stratum oriens and dentate gyrus (Fig. 5A,C). In comparison, in the $P c d h a^{\Delta C R / \Delta C R}$ mice, the density of the serotonergic fibers was dramatically increased in the stratum lacunosum-moleculare (Fig. 5B,D). A quantitative analysis revealed that the densities of the serotonergic fibers in the stratum lacunosum-moleculare and the stratum radiatum of CA1 region of $P c d h a^{\Delta C R / \Delta C R}$ mice compared with WT were $184 \%$ and $134 \%$, respectively (Fig. $5 F$ ). In contrast, in the stratum oriens and den- tate gyrus of the $P c d h a^{\Delta C R / \Delta C R}$ hippocampus, the densities were $44 \%$ and $21 \%$, respectively, of those levels in WT mice (Fig. $5 F)$. There was no apparent difference in serotonergic fiber density between WT and $P c d h a^{+/ \Delta C R}$ mice (Fig. $5 F$ ), nor was there a significant difference in the average density of the serotonergic fibers as a whole between the WT and $P c d h a^{\Delta C R / \Delta C R}$ mice (Fig. $5 F)$. These results suggest that the distribution pattern, but not total number, of serotonergic fibers in the hippocampus was changed in the mutants.

\section{Serotonergic somata in the rostral raphe nuclei}

It was possible that the altered distribution of serotonergic fibers in the brain of $P c d h a^{\Delta C R / \triangle C R}$ mice originated from changes in the distribution and/or number of serotonergic neurons in the rostral raphe nuclei. To investigate this possibility, we examined the brain stem of WT and $P c d h a^{\Delta C R / \triangle C R}$ mice by in situ hybridization histochemistry for SERT transcript. We did not find any apparent difference in the distribution of the serotonergic somata in the rostral raphe nuclei between WT and $P c d h a^{\Delta C R / \triangle C R}$ mice (supplemental Fig. $2 A-C$, available at www.jneurosci.org as supplemental material), and the number of SERT transcript-positive cells in these nuclei was unchanged (supplemental Fig. $2 D$, available at www.jneurosci.org as supplemental material).

\section{Serotonergic fibers in the developing brain of $P c d h a^{\Delta C R / \Delta C R}$ mice}

To understand how the abnormalities in the serotonergic projections developed in the $P c d h a^{\Delta C R / \triangle C R}$ mice, we examined their distribution pattern in the developing brain.

We first examined serotonergic fibers in the developing basal ganglia of WT and $P c d h a^{\Delta C R / \triangle C R}$ mice. At early postnatal stages (P7), WT serotonergic fibers were sparse in the caudate-putamen and globus pallidus (Fig. $6 \mathrm{~A}$ ), but some concentration was seen at the border between the two regions (Fig. $6 \mathrm{~A}$, arrows), and these findings were similar for the $P c d h a^{\Delta C R / \Delta C R}$ mice (Fig. $6 B$ ). At P21, the WT serotonergic fibers were fairly evenly distributed in the globus pallidus (Fig. $4 A$ ), whereas the $P c d h a^{\Delta C R / \Delta C R}$ serotonergic fibers were concentrated in the peripheral region and sparse in the central region (Fig. $4 B$ ). In the substantia nigra and geniculate nuclei, the serotonergic fibers of WT mice at P7 were sparse in the central regions and concentrated in the peripheral regions (Fig. 6C,E), and their distribution was similar to that in the Pcdha $a^{\Delta C R / \Delta C R}$ mice (Fig. $\left.6 D, F\right)$. At P21, WT serotonergic fibers were distributed throughout the substantia nigra and geniculate nuclei (Fig. $4 C, E$ ), whereas $P c d h a^{\Delta C R / \Delta C R}$ serotonergic fibers were concentrated in the peripheral regions and sparse in the 
central regions (Fig. $4 D, F$ ), as at P7 (although the innervation was denser) (Fig. $6 D)$. These results show serotonergic fibers of $P c d h a^{\Delta C R / \Delta C R}$ mice concentrating at the periphery of their target region, but barely innervating the interior of the target.

Next, we examined the distribution pattern of serotonergic axons in the developing hippocampus. In P0 WT mice, we detected serotonergic fibers in the stratum radiatum and stratum lacunosum-moleculare (Fig. 6G). At this developmental stage, the border between the stratum radiatum and the stratum lacunosum-moleculare was not well defined. There were also sparse serotonergic fibers in the stratum oriens of P0 WT mice (Fig. 6G), and only a few were detected in the dentate gyrus. The density of serotonergic fibers in the P0 Pcdha $a^{\Delta C R / \Delta C R}$ mice (Fig. 6G) was slightly higher than in WT mice (Fig. $6 H$ ), but their distribution patterns were essentially the same. At P21, the WT serotonergic fibers were widely distributed in the hippocampus (Fig. 5A), whereas those of the $P c d h a^{\Delta C R / \Delta C R}$ mice were concentrated in the stratum lacunosummoleculare and remained very sparse in the dentate gyrus (Fig. 5B), as described above. Thus, we concluded that in the $P c d h a^{\Delta C R / \Delta C R}$ mice, the serotonergic projections to their final target regions were incomplete, and apparently lacked their arborization.

Generation of mutant mice in which the Pcdha A-type cytoplasmic tail is deleted To determine how the CR deletions affected serotonergic target innervation, we investigated the potential roles of the two alternatively spliced A-type and B-type CRs that respectively encode the A-type and B-type cytoplasmic tail. We examined the distribution of serotonergic fibers in two types of Pcdha gene-targeted mice; $P c d h a^{\Delta A / \Delta A}$ and $P c d h a^{\Delta B / \Delta B}$ mice (Fig. $2 D, E)$. In $P c d h a^{\Delta B / \Delta B}$ mice, B-type Pcdha transcripts and proteins were not detectable whereas A-type Pcdha proteins were at normal (Fukuda et al., 2008). On the other hand, $P c d h a^{\Delta A / \Delta A}$ mice should produce truncated A-type Pcdha proteins that lack the A-type specific C-terminal region. We confirmed this truncated protein by immunoblotting with anti-Pcdha-CR and anti-Pcdha-c2 antibodies (Fig. 2F,G). However, and unexpectedly, $P c d h a^{\Delta A / \Delta A}$ mice did not produce B-type Pcdha transcripts, probably because of the loxP insertion near the splice donor site (Fig. 2G,H). Therefore, $P c d h a^{\Delta A / \Delta A}$ mice expressed only truncated Pcdha proteins that lacked the A-type cytoplasmic tail.

Mating between heterozygous $\left(P c d h a^{\Delta A /+}\right)$ mice resulted in homozygous, heterozygous, and WT mice at the expected Mendelian ratio. Homozygous $P c d h a^{\Delta A / \Delta A}$ mice were fertile and ap-
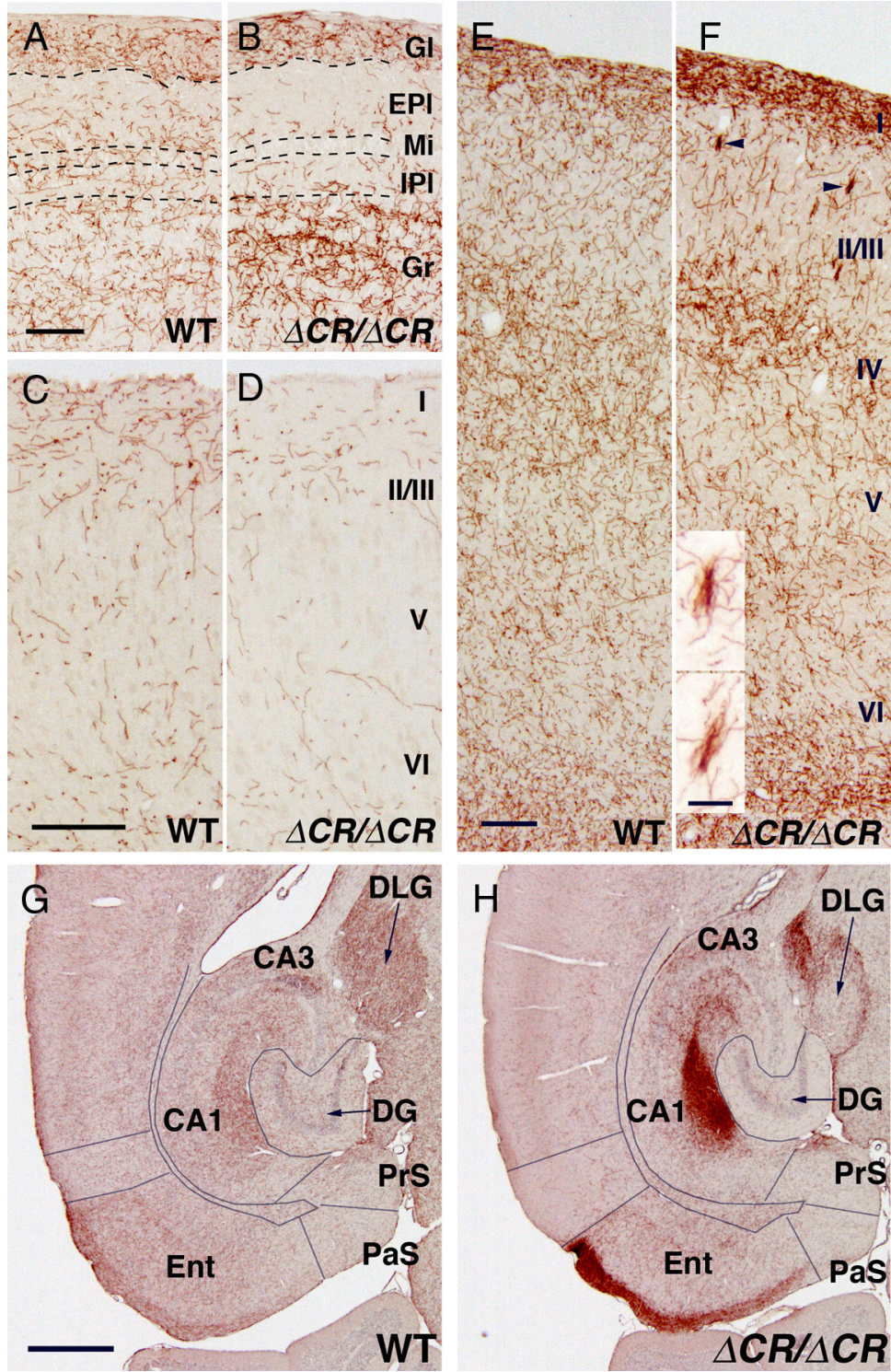

Figure 3. Altered distributions of serotonergic fibers in the cerebral cortex of $P c d h a^{\Delta C R / \triangle C R}$ mice. $A, B, S E R T$-i.p. fibers of WT $(A)$ and $P c d h a^{\Delta C R / \triangle C R}$ mice $(B)$ in sagittal sections of the dorsal olfactory bulb. Serotonergic fibers innervate the granule cell layer (Gr) in the $P c d h a^{\Delta C R / \triangle C R}$ mice more densely than in WT, and are less dense in the region from the external plexiform layer (EPI) to the inner plexiform layer (IPI). Dorsal is up; rostral is to the left. GI, glomerular layer; Mi, mitral cell layer. C, D, SERT-i.p. fibers of WT (C) and $P c d h a^{\Delta C R / \triangle C R}$ mice $(\boldsymbol{D})$ in coronal sections through the medial prefrontal cortex (cingulate cortex). Serotonergic fibers were more sparse in the $P c d h a^{\Delta C R / \triangle C R}$ brain than in WT, throughout the cortical layers. Medial is up; dorsal is to the left. E, F, SERT-i.p. axons of WT $(\boldsymbol{E})$ and $P\left(d h a^{\Delta C R / \triangle C R}\right.$ mice $(\boldsymbol{F})$ in sagittal sections through the rostral primary motor cortex. Serotonergic axons innervated layers I, IV, and VI more densely in the $P c d h a^{\Delta C R / \Delta C R}$ mice than in WT mice. In layer II/III of the $P c d h a^{\Delta C R / \Delta C R}$ mice, short clumped serotonergic fibers (arrowheads, enlarged at bottom; scale bar, $20 \mu \mathrm{m}$ ) were frequently observed. Dorsal is up; rostral is to the left. $\boldsymbol{G}, \boldsymbol{H}$, SERT-i.p. fibers of WT $(\boldsymbol{G})$ and $P c d h a^{\Delta C R / \Delta C R}$ mice $(\boldsymbol{H})$ in horizontal sections through the hippocampus and entorhinal cortex. Serotonergic fibers innervated the superficial layer $(\boldsymbol{I})$ of the entorhinal cortex (Ent) more densely in the $P c d h a^{\Delta C R / \Delta C R}$ mice than in WT mice. Rostral is up; lateral is to the left. DG, dentate gyrus; DLG, dorsal lateral geniculate nucleus; PaS, parasubiculum; PrS, presubiculum. Scale bars: $(\boldsymbol{A}-\boldsymbol{F}), 200 \mu \mathrm{m} ;(\boldsymbol{G}, \boldsymbol{H}), 500 \mu \mathrm{m}$.

peared the same as WT mice at $4-8$ weeks of age, but their body weight was below that of WT mice from 12 to 96 weeks of age (supplemental Fig. $3 A$, available at www.jneurosci.org as supplemental material), an effect that was also seen in homozygous $P c d h a^{\Delta C R / \Delta C R}$ mice older than 72 weeks (supplemental Fig. $3 B$, available at www.jneurosci.org as supplemental material). In addition, by 36 weeks of age, $P c d h a^{\Delta A / \Delta A}$ and $P c d h a^{\Delta C R / \Delta C R}$ mice gradually developed lesions on their head, neck, and snout regions (supplemental Figs. $4 A-D, 5 A, B$, available at www. jneurosci.org as supplemental material). At 96 weeks, approxi- 

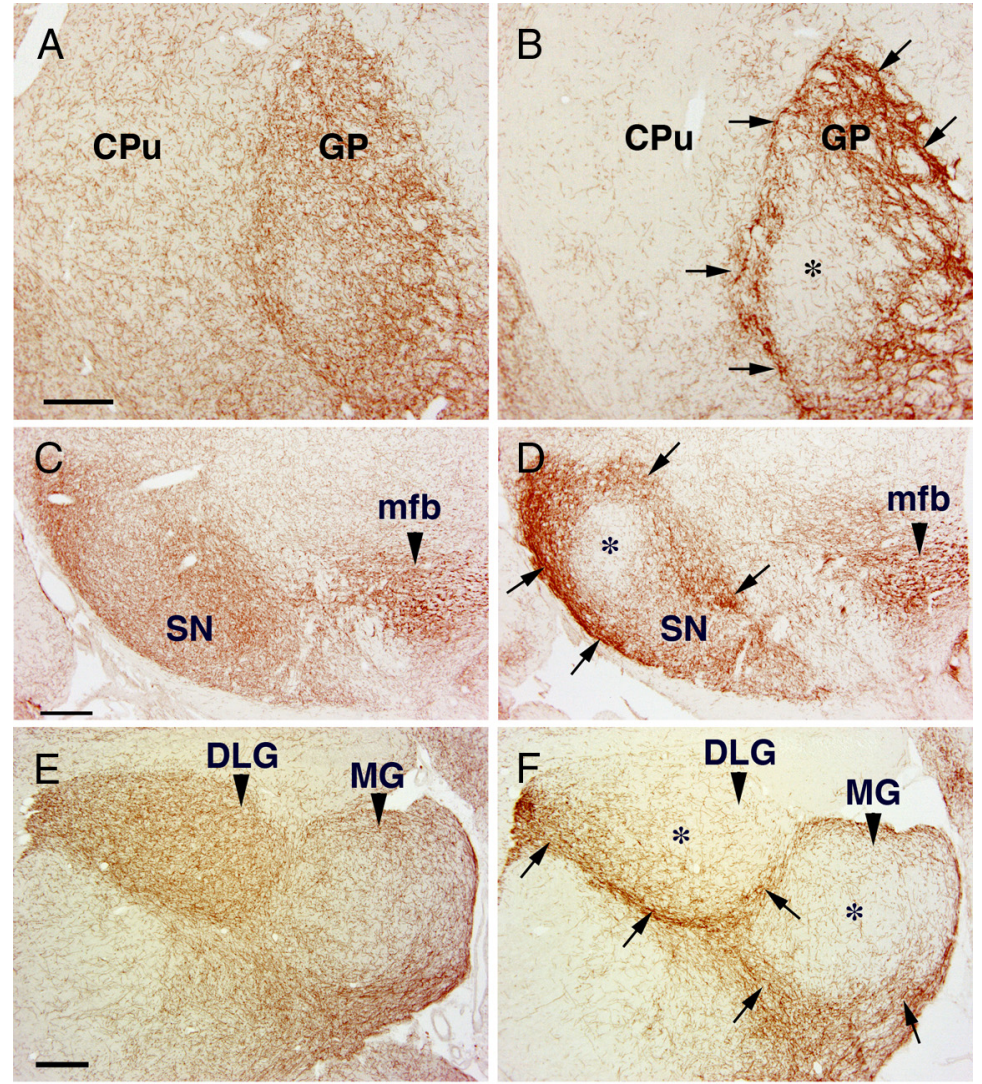

WT
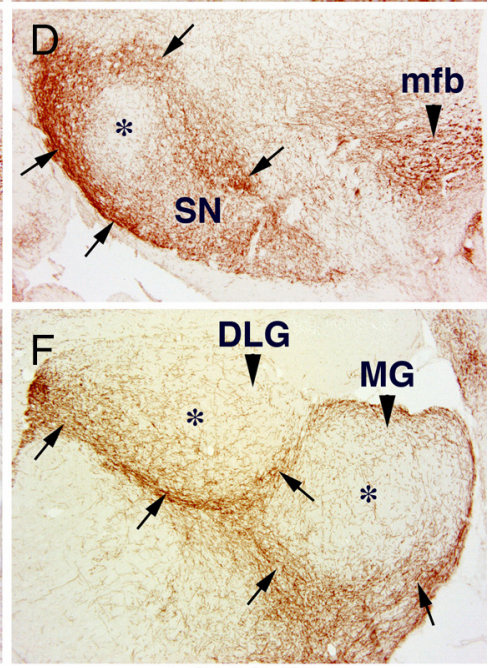

$\Delta C R / \Delta C R$

Figure 4. Altered distributions of serotonergic fibers in the basal ganglia and thalamus of $P c d h a^{\Delta C R / \triangle C R}$ mice. $A, B, S E R T$-i.p. fibers in coronal sections through the caudate-putamen (CPu) and globus pallidus (GP) of WT $(\boldsymbol{A})$ and $P c d h a^{\Delta C R / \Delta C R}(\boldsymbol{B})$ mice at $P 21$. Lateral is to the left. The serotonergic axons of the $P c d h a^{\Delta C R / \Delta C R}$ mice $(\boldsymbol{B})$ were less sparse in the CPu than in WT mice $(\boldsymbol{A})$. $\boldsymbol{C}$, $D$, SERT-i.p. fibers in coronal sections through the substantia nigra (SN) of WT (C) and $P c d h a^{\Delta C R / \Delta C R}$ mice $(\boldsymbol{D})$ at P21. Lateral is to the left. There was no apparent difference in the density of serotonergic fibers in the medial forebrain bundle $(\mathrm{mfb})$ ofWT $(C)$ and $P c d h a^{\Delta C R / \Delta C R}$ mice (D).E, $\boldsymbol{F}$, SERT-i.p. fibers in sagittal sections of the dorsal lateral (DLG) and medial geniculate nuclei (MG) of WT $(\boldsymbol{E})$ and $P c d h a^{\Delta C R / \Delta C R}(\boldsymbol{F})$ mice at P21. Rostral is to the left. $\boldsymbol{A}-\boldsymbol{F}$, In WT mice the GP, SN, DLG, and MG were almost evenly innervated by serotonergic fibers, whereas in the $P c d h a^{\Delta C R / \Delta C R}$ mice, serotonergic fibers more densely concentrated around these nuclei (arrows) and were sparse in the central regions of these nuclei (asterisks). Scale bars: $A-F, 200 \mu \mathrm{m}$.

mately half of the $P c d h a^{\Delta A / \Delta A}$ mice had some lesions on their bodies. These old, injured homozygous $P c d h a^{\Delta A / \Delta A}$ and $P c d h a^{\Delta C R / \triangle C R}$ mice groomed themselves more frequently than WT mice, leading to the injuries.

\section{Loss of the Pcdha A-type, but not the B-type, cytoplasmic region causes abnormal serotonergic projections}

Next, we examined the projections of the serotonergic fibers in the $P c d h a^{\Delta A / \Delta A}$ and $P c d h a^{\Delta B / \Delta B}$ mice, and compared them with WT and with the abnormalities found in the $P c d h a^{\Delta C R / \Delta C R}$ mice. In the $P c d h a^{\Delta A / \Delta A}$ mice, the distribution pattern of the serotonergic fibers in the hippocampus (Fig. 7B) was abnormal compared with WT mice (Fig. 7A), and quite similar to that of the $P c d h a^{\Delta C R / \Delta C R}$ mice (Fig. 5B). A quantitative analysis showed that the densities of the serotonergic fibers of $P c d h a^{\Delta A / \Delta A}$ mice were significantly higher in the stratum lacunosum-moleculare (170\%) and lower in the dentate gyrus (41\%) compared with WT mice (Fig. 7D). In contrast to the $P c d h a^{\Delta A / \Delta A}$ mice, the densities of serotonergic fibers in the $P c d h a^{+/ \Delta A}$ and $P c d h a^{\Delta B / \Delta B}$ mice were similar to those of WT mice (Fig. $7 A-D$, data not shown). Furthermore, the serotonergic projections of the $P c d h a^{\Delta A / \Delta A}$ mice, but not those of the $P c d h a^{+/ \Delta A}$ or $P c d h a^{\Delta B / \Delta B}$ mice, were essentially the same as for the $P c d h a^{\triangle C R / \Delta C R}$ mice in the cerebral cortex, hippocampus, basal ganglia and thalamus. In addition, the abnormal projec- tions in the $P c d h a^{\Delta A / \Delta A}$ were not detectable within the first several postnatal days, as with the Pcdha $a^{\Delta C R / \Delta C R}$ mice. These data indicated that the Pcdha A-type splice variant, but not the B-type variant, is important for the normal innervation of target regions by serotonergic projections from the raphe nuclei, and for their even distribution.

\section{Analysis of monoamine levels in the hippocampus of Pcdha gene-targeted mice}

The amount of serotonin is higher in the hippocampus of the hypomorphic Pcdha A-type mutants (Pcdha $a^{\Delta \text { Aneo/ } \triangle \text { Aneo }}$ and $\left.P c d h a^{\Delta B n e o / \Delta B n e o}\right)$ than in the $P c d h a^{\Delta B / \Delta B}$ mouse (Fukuda et al., 2008). Therefore, we examined the serotonin levels in the hippocampus of adult $P c d h a^{\Delta A / \Delta A}$ and $P c d h a^{\Delta C R / \Delta C R}$ mice. In the hippocampus of 10 -week-old mice, the amount of serotonin was significantly higher in the $P c d h a^{\Delta A / \Delta A}(p<0.05)$ and $P c d h a^{\Delta C R / \Delta C R}$ mice $(p<0.001)$ than in WT mice, and the amount of 5-hydroxyindoleacetic acid (the main metabolite of serotonin) was significantly higher in the $P c d h a^{\Delta A / \Delta A}$ mice $(p<0.01)$, although the amount of noradrenalin for all the genotypes was the same (Fig. 8A,B). These results demonstrated that the serotonin level in the hippocampus was strongly associated with the in vivo function of the Pcdha A-type protein.

\section{Cortical barrel fields in the Pcdha $^{\Delta \mathrm{CR} / \Delta \mathrm{CR}}$ mice}

It has been shown that serotonin is a key neurotransmitter to form the cortical barrels, which are cellular aggregates in the somatosensory cortex and represent somatotopic organization for sensory inputs, especially inputs from vibrissae on the face (Woolsey and Van der Loos, 1970). Thus, we examined the cortical barrels to investigate the consequence of the altered serotonergic system in the $P c d h a^{\Delta C R / \Delta C R}$ mice. However, we could not detect the structural abnormalities in the barrel fields of the $P c d h a^{\Delta C R / \Delta C R}$ mice by either of SERT immunostaning or cytochrome oxidase histochemistry (supplemental Fig. $6 A-D$, available at www.jneurosci. org as supplemental material).

\section{Discussion}

Serotonergic neurons, like the other monoaminergic neurons, project their axons from the brain stem, including the raphe nuclei, to most regions of the CNS. However, the mechanism that controls the global projections of serotonergic neurons to their targets is largely unknown. Here we found that Pcdha transcripts were strongly expressed in the raphe nuclei from embryonic stages through adulthood, and therefore we examined the distribution of serotonergic projections from these nuclei in several mouse lines encoding mutant Pcdha proteins.

The deletion of the Pcdha-CR exons ( $P c d h a^{\Delta C R / \Delta C R}$ mice) led to abnormally distributed serotonergic fibers in many brain regions by $\mathrm{P} 21$. These abnormalities were also detected in a full 

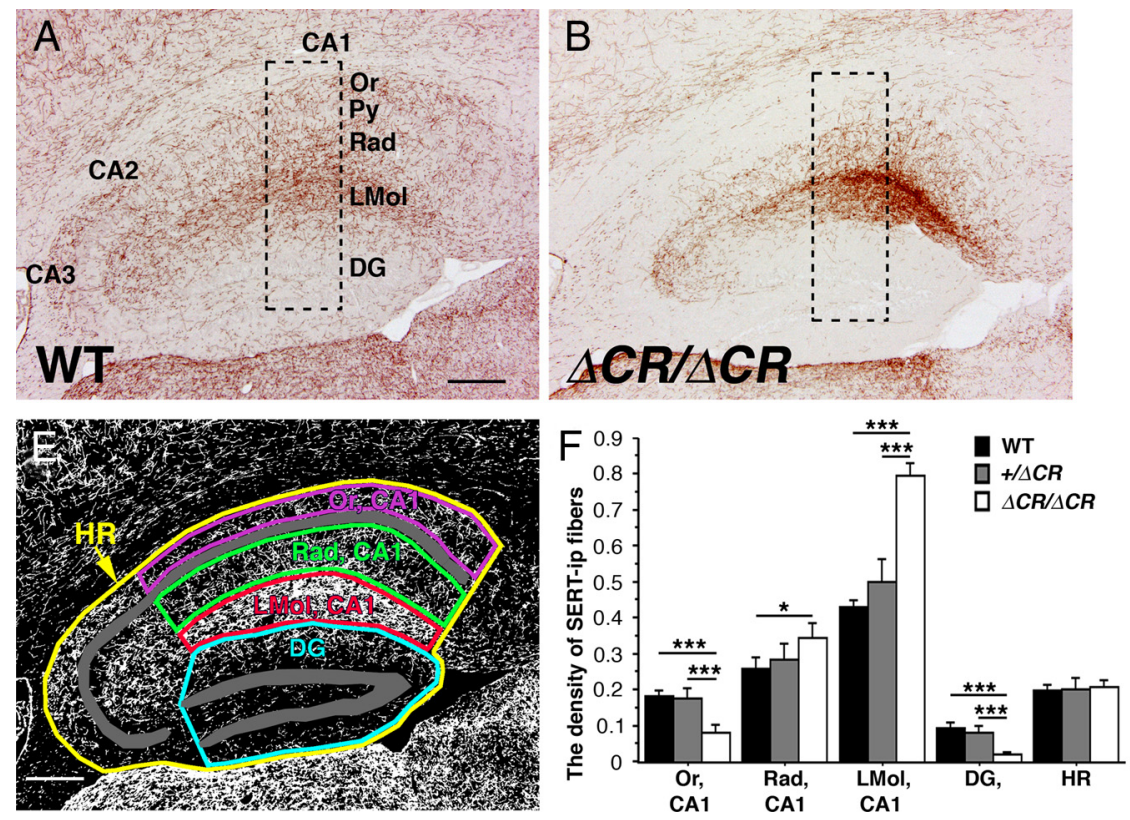

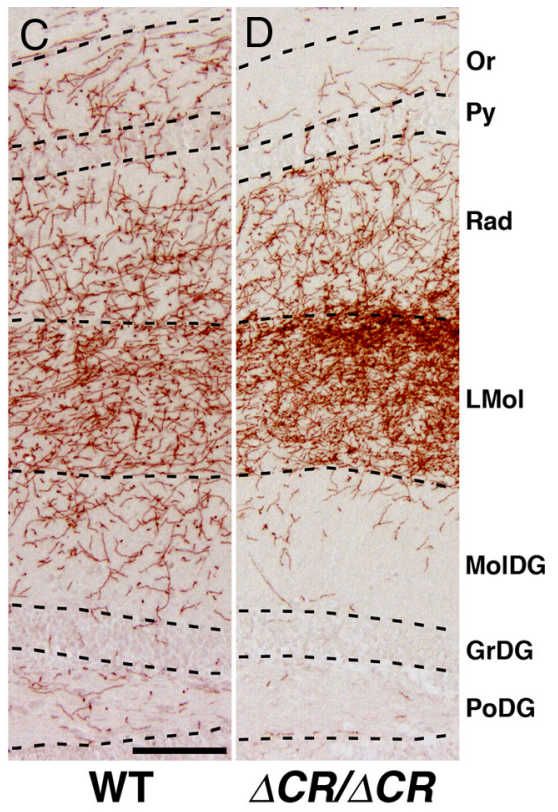

Figure 5. Abnormal distributions of serotonergic fibers within the hippocampus of $P c d h a^{\Delta C R / \Delta C R}$ mice. $A-D$, SERT-i.p. fibers in sagittal sections of the dorsal hippocampus at P21. Dorsal is up; rostral is to the left. The fibers of WT mice $(\boldsymbol{A}, \boldsymbol{C})$ were distributed throughout the hippocampal region, but those of $P\left(d h a^{\Delta C R / \Delta C R}\right.$ mice $(\boldsymbol{B}, \boldsymbol{D})$ were mainly distributed within the stratum radiatum (Rad) and stratum lacunosum-moleculare (LMol), and they were sparse in the dentate gyrus (DG), the pyramidal cell layer (Py), and stratum oriens (Or). $\boldsymbol{C}$ and $\boldsymbol{D}$ are higher magnification images of the boxed areas in $\boldsymbol{A}$ and $\boldsymbol{B}$, respectively. GrDG, Granular layer of the DG; MolDG, molecular layer of the DG; PoDG, polymorph layer of the DG. $\boldsymbol{E}$, To quantify SERT-i.p. fibers, photographs of the dorsal hippocampal region were converted into binary images, and compartmentalized into Or, CA1; Rad, CA1; LMol, CA1; DG; and HR (hippocampal region, the sum of the CAs and DG). F, Quantification of SERT-i.p. fibers in WT $(n=4), P c d h a^{+/ \Delta C R}(n=4)$, and $P c d h a^{\Delta C R / \Delta C R}$ mice $(n=4)$. The fiber densities of the $P c d h a^{\Delta C R / \Delta C R}$ mice were significantly higher in the Rad and LMol, and lower in the Or and DG than those of WT mice. ${ }^{*} p<0.05,{ }^{* * *} p<0.001$. Scale bars: $(\boldsymbol{A}, \boldsymbol{B}), 200 \mu \mathrm{m} ;(\boldsymbol{C}, \boldsymbol{D}), 100 \mu \mathrm{m}$.

knock-out mutant of the Pcdha, in which the Pcdha gene cluster is completely deleted (Okayama A, Hasegawa S, Hirabayashi T, Katori S, Yagi T, unpublished data). Early in postnatal life (before the formation of terminal arbors in the target regions), the distribution pattern of serotonergic fibers in the $P c d h a^{\Delta C R / \Delta C R}$ mice was similar to that in WT mice. However, at P21, the distribution of serotonergic axons in $P c d h a^{\Delta C R / \Delta C R}$ mice was substantially altered. That is, the axons approached their target regions normally, but they did not form the extensive axonal arbors seen in adult WT mice at the same age, when the serotonergic projections are almost complete.

Lidov and Molliver (1982) proposed that the ontogeny of the serotonergic axonal projections is divided into three periods: first, axon elongation (E13-E16); second, development of selective pathways (E15-E19); and third, terminal field development (E19-P21). Our results indicate that the Pcdha proteins may function during the final period, during terminal field development. The $P c d h a^{\Delta C R / \Delta C R}$ mice showed low densities of innervating fibers in the central part of several target regions, such as the globus pallidus and substantia nigra, which could be explained by insufficient terminal arborization of the serotonergic fibers, which did penetrate the targets' periphery. Unlike the fiber termini, serotonergic axon bundles, such as the medial forebrain bundle, appeared normal in $P c d h a^{\Delta C R / \Delta C R}$ mice (Fig. 4C,D). During the terminal field development, the formation of serotonergic terminal arborization is dependent on the maturation of other elements in the local neuronal circuitry (Lidov and Molliver, 1982), suggesting that the Pcdha proteins might be involved in the interactions that promote terminal field development.

Factors that regulate serotonergic axon outgrowth and terminal arborization have been suggested by studies on the ontogeny of serotonergic innervation. S-100 $\beta$, a $\mathrm{Ca}^{2+}$-binding protein secreted from astroglia, functions as a growth factor in vitro by inducing serotonergic sprouting (Azmitia et al., 1990; Haring et al., 1993), but S-100 $\beta$-null mice show normal serotonergic projections (Nishiyama et al., 2002). Brain-derived neurotrophic factor (BDNF) can induce serotonergic axonal growth in the adult cortex (Mamounas et al., 1995, 2000), and serotonergic projections are normal in younger $\mathrm{BDNF}^{+/-}$mice, but a progressive loss of serotonergic fibers is observed when they are 12-18 months old (Lyons et al., 1999). Thus, the secreted S-100 $\beta$ and BDNF proteins regulate serotonergic projections, and the loss of either may be compensated for by other extracellular proteins, at least early in development. The cytoplasmic protein GAP-43, a growth-associated protein, is strongly expressed in monoaminergic neurons (Bendotti et al., 1991; Wotherspoon et al., 1997), and is a regulator for serotonergic projections. GAP43-null mice have abnormal serotonergic projections, but the abnormalities are different from those of our $P c d h a^{\Delta C R / \Delta C R}$ mice. At P0, few serotonergic fibers in GAP-43-null mice have arrived at the hippocampus (Donovan et al., 2002), whereas in Pcdha mutants the fibers appear to arrive at the target almost normally. At P21, in the Pcdha mutants the amount of serotonergic axons arriving at the hippocampal region was normal, although their distribution within the hippocampal subregions was abnormal (Fig. 5F). In contrast, in GAP-43-null mice, the density of serotonergic axons arriving at the hippocampal region was lower, compared with WT mice (Donovan et al., 2002). Thus, in the regulation of serotonergic projections, GAP-43's function may be required in early developmental stages, and the roles of the Pcdha proteins may be significant only later in development.

We recently demonstrated that the OSNs of $P c d h a^{\Delta C R / \Delta C R}$ mice project abnormally to the olfactory bulb (Hasegawa et al., 2008). In the olfactory bulb of $P c d h a^{\Delta C R / \Delta C R}$ mice, axons expressing a single olfactory receptor (M71 or MOR23) do not coalesce into one glomerulus on each side of the olfactory bulb, but instead form multiple 


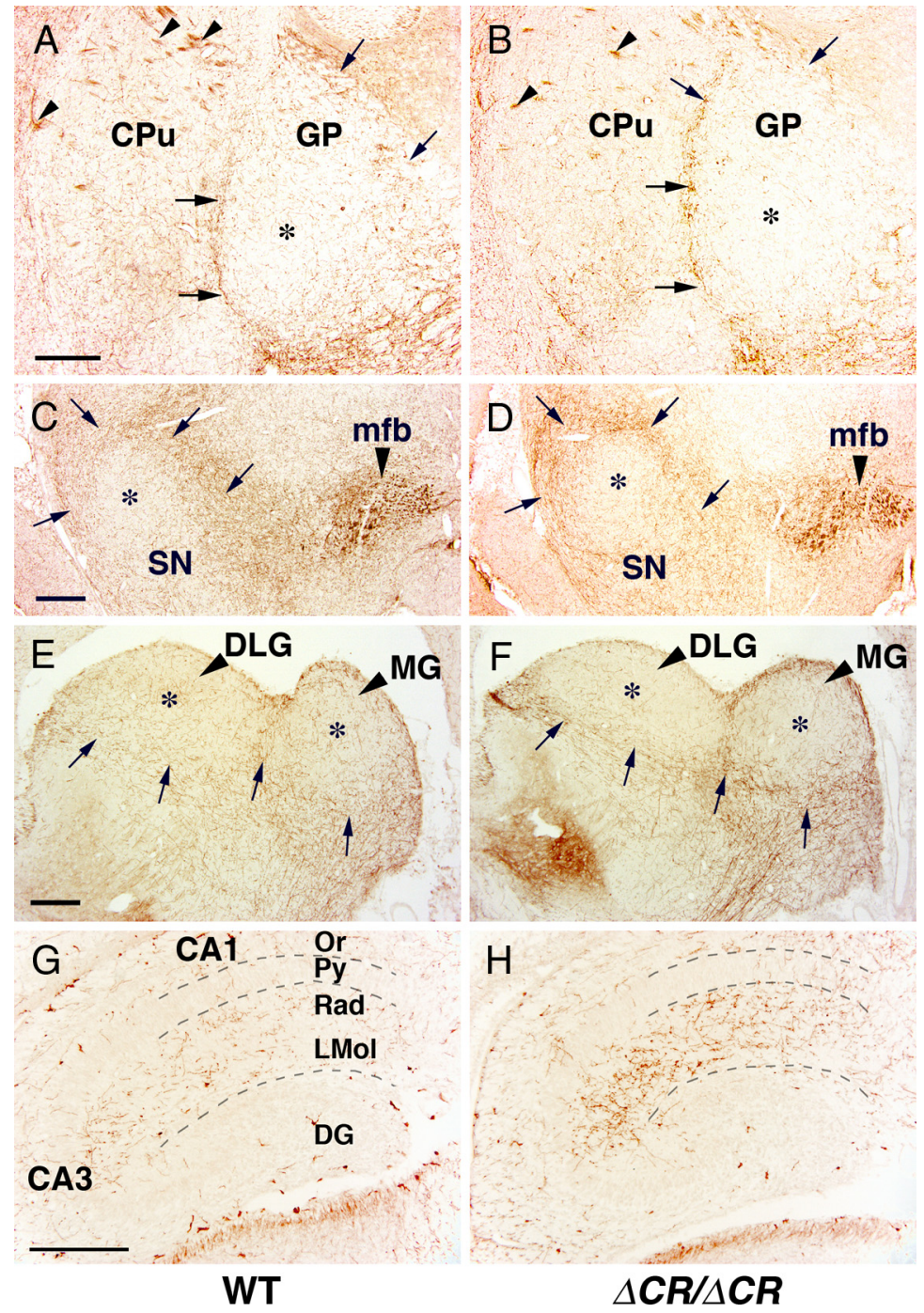

Figure 6. Serotonergic fibers in the developing brain of $P\left(d h a^{\Delta C R / \Delta C R}\right.$ mice. $A-D$, SERT-i.p. fibers in coronal sections through the globus pallidus (GP) $(\boldsymbol{A}, \boldsymbol{B})$ and substantia nigra (SN) $(\boldsymbol{C}, \boldsymbol{D})$ of WT $(\boldsymbol{A}, \boldsymbol{C})$ and $P c d h a^{\Delta C R / \Delta C R}(\boldsymbol{B}, \boldsymbol{D})$ mice at $P 7$. Lateral is to the left. Thalamocortical axons were SERT-i.p. ( $\boldsymbol{A}, \boldsymbol{B}$, arrowheads). There was no apparent difference in the density of serotonergic fibers in the medial forebrain bundle $(\mathrm{mfb})$ of WT $(\boldsymbol{C})$ and $P c d h a^{\Delta C R / \Delta C R}$ mice (D). $\boldsymbol{E}, \boldsymbol{F}$, SERT-i.p. fibers in sagittal sections of dorsal lateral (DLG) and medial geniculate nuclei (MG) of WT $(\boldsymbol{E})$ and $P\left(d h a^{\Delta C R / \Delta C R}(\boldsymbol{F})\right.$ mice at P7. Rostral is to the left. $\boldsymbol{A}-\boldsymbol{F}$, The distribution patters of serotonergic fibers of WT $(\boldsymbol{A}, \boldsymbol{C}, \boldsymbol{E})$ were similar to those of the $P c d h a^{\Delta C R / \Delta C R}$ mice $(\boldsymbol{B}, \boldsymbol{D}, \boldsymbol{F})$, and slightly concentrated around the GP, SN, DLG, and MG (arrows in $\boldsymbol{A}-\boldsymbol{F}$ ), and were sparse in the center regions of these nuclei ( $\boldsymbol{A}-\boldsymbol{F}$, asterisks). $\boldsymbol{G}, \boldsymbol{H}$, SERT-i.p. fibers in sagittal sections of the dorsal hippocampus of WT $(\boldsymbol{G})$ and $P c d h a^{\Delta C R / \Delta C R}$ mice $(\boldsymbol{H})$ at $P 0$. Rostral is to the left. The fibers of WT $(\boldsymbol{G})$ and $P c d h a^{\Delta C R / \Delta C R}$ mice $(\boldsymbol{H})$ were dense in the stratum radiatum (Rad) and stratum lacunosum-moleculare (LMol), and sparse in the stratum oriens (Or), pyramidal cell layer (Py), and dentate gyrus (DG). Scale bars: $\boldsymbol{A}-\boldsymbol{H}, 200 \mu \mathrm{m}$.

small glomeruli that persist even at P30 and P60. In WT mice, abnormal axonal projections to small multiple glomeruli are observed in the developing olfactory bulb; however, these supernumerary glomeruli are gradually eliminated during postnatal maturation. Therefore, the abnormality of the OSN projections in the $P c d h a^{\Delta C R / \Delta C R}$ mice is consistent with the idea that Pcdha proteins function in the final maturation stage of axonal projections.

In the present study, we could not propose suitable models to explain the phenotype of serotonergic fibers in the Pcdha $a^{\Delta C R / \Delta C R}$ mice because the mechanism for how Pcdha proteins modify serotonergic axon outgrowth and terminal arborization is still unclear. This ignorance is considerably due to the lack of the information on the adhesion properties and subcellular localization of Pcdha proteins. Although it has been suggested that Pcdha proteins interact with $\beta 1$-integrin in a trans-heterophilic manner (Mutoh et al., 2004), trans-homophilic adhesion of Pcdha pro- teins could not be detected (Morishita et al., 2006). Furthermore, the subcellular localization of Pcdha proteins in serotonergic neurons and their targets could not be determined. During the formation of serotonergic terminal arbors, most of the neurons in the brain express detectable Pcdha transcripts. Our immunohistochemical examination with the Pcdha antibodies demonstrate intense immunoreactivity in the serotonergic somata but fail to determine the subcellular localization of the Pcdha proteins in the target regions of the serotonergic axons; Pcdha immunoreactivity was rather homogeneously distributed in the neuropil (data not shown, Hasegawa et al., 2008). To clarify the subcellular localization of Pcdha proteins, further studies including immunoelectron microscopy will be necessary.

Here we demonstrated that the A-type cytoplasmic tail of Pcdha proteins is important for the normal distribution of serotonergic projections. The A-type cytoplasmic tail of Pcdhas is reported to associate with neurofilament $\mathrm{M}$ (TrianaBaltzer and Blank, 2006). Furthermore, Pcdha proteins are subject to matrix metalloprotease cleavage followed by presenilin-dependent intramembrane proteolysis, and the cleaved portion of the A-type cytoplasmic region translocates into the nucleus from the plasma membrane (Bonn et al., 2007). Therefore, the A-type cytoplasmic region may play a crucial role in signal transduction.

Although the signals transduced by the Pcdha proteins are not known, some possibilities have been suggested by recent findings. For example, a similar phenotype of abnormal, clumped axons was reported for the retinal axons of Dscam (Down syndrome cell adhesion molecule) mutant mice (Fuerst et al., 2008). Mammalian DSCAM, an Ig superfamily member, shows homophilic binding (Agarwala et al., 2000); it promotes self-avoidance (isoneuronal) for arborizing processes and inhibits the fasciculation of processes from different neurons (heteroneuronal) (Fuerst et al., 2008). This similarity raises the possibility that the Pcdha protein might function in the self-avoidance of serotonergic neurons. A-type cytoplasmic tail may transduce repulsive signals in the serotonergic neurons. The defect of self-avoidance may directly influence serotonergic axon outgrowth and terminal arborization. Alternatively, the insufficient self-avoidance may affect the configuration of recurrent collaterals of serotonergic neurons which regulate the activity of these neurons, and then indirectly change the terminal arbors by activity-dependent mechanisms.

Here we demonstrated that $P c d h a$ molecules play significant roles in the establishment of normal serotonergic projections in every brain region we studied. We also found that in $P c d h a^{\Delta C R / \Delta C R}$ and $P c d h a^{\Delta A / \Delta A}$ mice, the serotonin levels of the hippocampus were significantly increased, compared with WT. Previously, we reported 

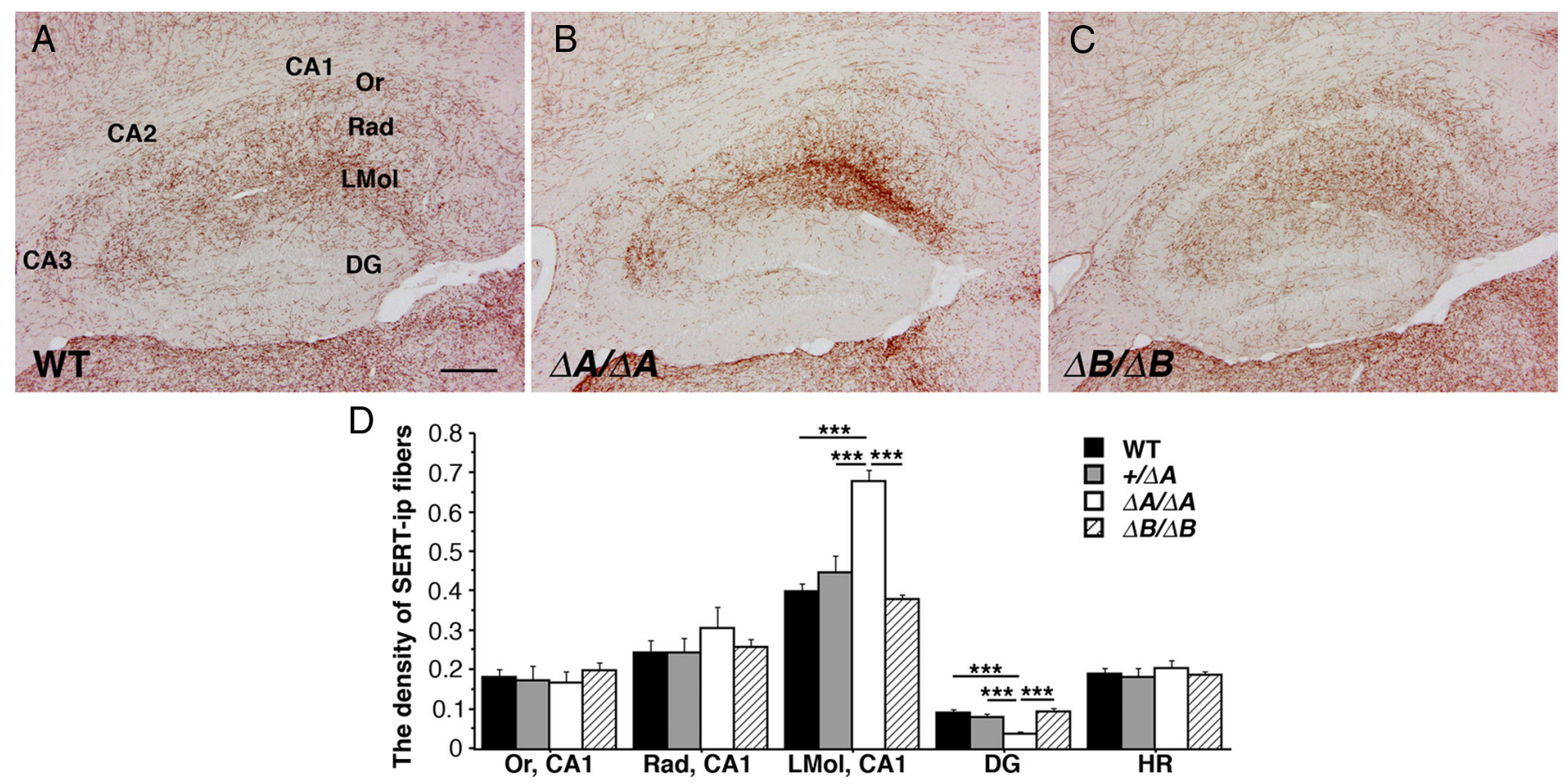

Figure 7. Loss of the Pcdha A type cytoplasmic region, but not the B-type, causes abnormal serotonergic projections. A-C, SERT-i.p. fibers in sagittal sections of the dorsal hippocampus at P21. The fiber distributions in the $P c d h a^{\Delta B / \Delta B}(\boldsymbol{C})$ mice were similar to those of WT mice $(\boldsymbol{A})$. In the $P c d h a^{\Delta A / \Delta A}$ mice $(\boldsymbol{B})$, the fiber distributions were abnormal, as in the $P c d h a^{\Delta C R / \Delta C R}$ mice $(F i g .5 D)$. $\boldsymbol{D}$, Binary, compartmentalized images of WT $(n=4), P c d h a^{+/ \Delta A}(n=4), P c d h a^{\Delta A / \Delta A}(n=4)$, and $P c d h a^{\Delta B / \Delta B}$ mice $(n=4)$ were used to quantify the fiber distributions. The fiber densities of $P c d h a^{+/ \Delta A}$ and $P c d h a^{\Delta B / \Delta B}$ mice were similar to those of WT mice. In contrast, the fiber densities of $P\left(d h a^{\Delta A / \Delta A}\right.$ mice were significantly higher in the LMol, and lower in the DG than those of WT mice. ${ }^{* * *} p<0.001$. Scale bars: $A-C, 200 \mu \mathrm{m}$.

that hypomorphic Pcdha A-type mutant mice $\left(P c d h a^{\Delta \text { Bneo/ } \Delta \text { Bneo }}\right)$, in which Pcdha B-type transcripts are not detected and the expression level of Pcdha A-type transcripts is reduced, show an increased amount of serotonin in the hippocampus, and enhanced contextual fear conditioning and abnormal spatial learning (Fukuda et al., 2008). Together, these data are consistent with the idea that abnormal levels of serotonin in the hippocampus result from mutations of the Pcdha cytoplasmic tail, and that the altered serotonin levels could affect behavior.

The human protocadherin gene clusters (Pcdha, $P c d h b$, and $P c d h g)$ are located on chromosome 5q31 (Wu and Maniatis, 1999). This locus is associated with BD (Lewis et al., 2003; Hong et al., 2004; Herzberg et al., 2006; Kerner et al., 2007). A recent study demonstrated a significant increase in homozygosity of the minor allele, which contains a single-nucleotide polymorphism in a putative enhancer for the Pcdha gene, in patients with BD (Pedrosa et al., 2008).

Whether or not the association with BD holds up, abnormal serotonergic innervation is implicated in a number of neuropsychiatric disorders, including depression, anxiety, schizophrenia, and autism (Baumgarten and Grozdanovic, 1995; Hen, 1996; Mann, 1998). Here, our observation that Pcdhas contributed to appropriate serotonergic projections in much if not all of the brain, suggests that Pcdhas could also be involved with the pathogenic mechanisms of a number of neuropsychiatric disorders, via their regulation of serotonergic projections.
A
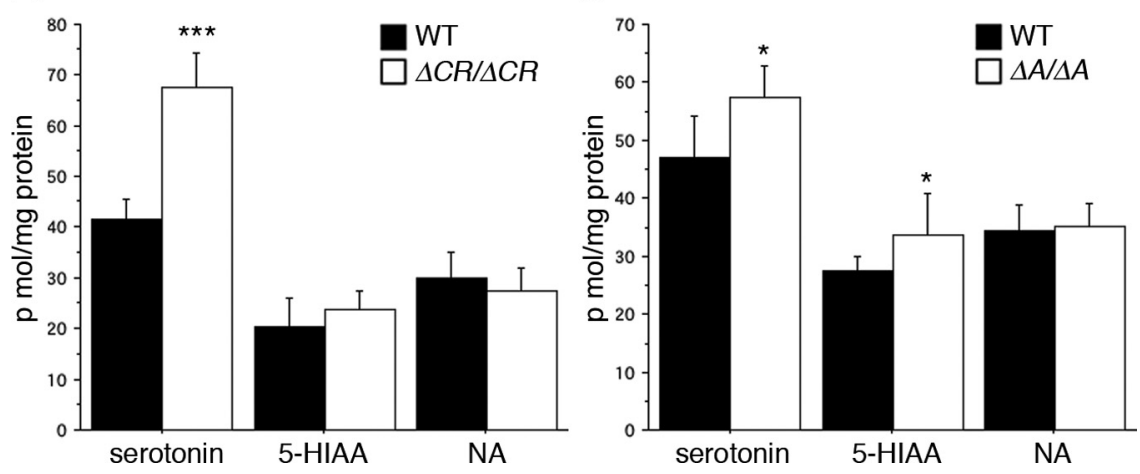

Figure 8. The analysis of monoamine levels in the hippocampus of $P c d h a^{\Delta C R / \Delta C R}$ and $P c d h a^{\Delta A / \Delta A}$ mice. $A$, The amount of serotonin, 5-hydroxyindoleacetic acid (5-HIAA), and noradrenalin (NA) in the hippocampus was measured by HPLC assay. In the $P c d h a^{\triangle C R / \Delta C R}$ mice $(n=8)$, the serotonin level was significantly higher than in the WT mice $(n=8)$. There was no significant difference in 5-HIAA and NA levels between WT and $P c d h a^{\Delta C R / \Delta C R}$ mice. $B, \ln P c d h a^{\Delta A / \Delta A}$ mice $(n=10)$, the levels of serotonin and 5-HIAA were significantly higher than in WT mice $(n=8)$. There was no significant difference in NA levels between WT and Pcdha $a^{\Delta A / \Delta A}$ mice. ${ }^{*} p<0.05,{ }^{* * *} p<0.001$.

\section{References}

Agarwala KL, Nakamura S, Tsutsumi Y, Yamakawa K (2000) Down syndrome cell adhesion molecule DSCAM mediates homophilic intercellular adhesion. Brain Res Mol Brain Res 79:118-126.

Azmitia EC, Dolan K, Whitaker-Azmitia PM (1990) S-100B but not NGF, EGF, insulin or calmodulin is a CNS serotonergic growth factor. Brain Res 516:354-356.

Baumgarten HG, Grozdanovic Z (1995) Psychopharmacology of central serotonergic systems. Pharmacopsychiatry 28 [Suppl 2]:73-79.

Bendotti C, Servadio A, Samanin R (1991) Distribution of GAP-43 mRNA in the brain stem of adult rats as evidenced by in situ hybridization: localization within monoaminergic neurons. J Neurosci 11:600-607.

Bonn S, Seeburg PH, Schwarz MK (2007) Combinatorial expression of alpha- and gamma-protocadherins alters their presenilin-dependent processing. Mol Cell Biol 27:4121-4132. 
Carroll P, Gayet O, Feuillet C, Kallenbach S, de Bovis B, Dudley K, Alonso S (2001) Juxtaposition of CNR protocadherins and reelin expression in the developing spinal cord. Mol Cell Neurosci 17:611-623.

Donovan SL, Mamounas LA, Andrews AM, Blue ME, McCasland JS (2002) GAP-43 is critical for normal development of the serotonergic innervation in forebrain. J Neurosci 22:3543-3552.

Esumi S, Kakazu N, Taguchi Y, Hirayama T, Sasaki A, Hirabayashi T, Koide T, Kitsukawa T, Hamada S, Yagi T (2005) Monoallelic yet combinatorial expression of variable exons of the protocadherin-alpha gene cluster in single neurons. Nat Genet 37:171-176.

Fuerst PG, Koizumi A, Masland RH, Burgess RW (2008) Neurite arborization and mosaic spacing in the mouse retina require DSCAM. Nature 451:470-474.

Fukuda E, Hamada S, Hasegawa S, Katori S, Sanbo M, Miyakawa T, Yamamoto T, Yamamoto H, Hirabayashi T, Yagi T (2008) Downregulation of protocadherin-alpha $\mathrm{A}$ isoforms in mice changes contextual fear conditioning and spatial working memory. Eur J Neurosci 28:1362-1376.

Haring JH, Hagan A, Olson J, Rodgers B (1993) Hippocampal serotonin levels influence the expression of S100 beta detected by immunocytochemistry. Brain Res 631:119-123.

Hasegawa S, Hamada S, Kumode Y, Esumi S, Katori S, Fukuda E, Uchiyama Y, Hirabayashi T, Mombaerts P, Yagi T (2008) The protocadherin-alpha family is involved in axonal coalescence of olfactory sensory neurons into glomeruli of the olfactory bulb in mouse. Mol Cell Neurosci 38:66-79.

Hen R (1996) Mean genes. Neuron 16:17-21.

Herzberg I, Jasinska A, García J, Jawaheer D, Service S, Kremeyer B, Duque C, Parra MV, Vega J, Ortiz D, Carvajal L, Polanco G, Restrepo GJ, López C, Palacio C, Levinson M, Aldana I, Mathews C, Davanzo P, Molina J, et al. (2006) Convergent linkage evidence from two Latin-American population isolates supports the presence of a susceptibility locus for bipolar disorder in 5q31-34. Hum Mol Genet 15:3146-3153.

Hong KS, McInnes LA, Service SK, Song T, Lucas J, Silva S, Fournier E, León P, Molina J, Reus VI, Sandkuijl LA, Freimer NB (2004) Genetic mapping using haplotype and model-free linkage analysis supports previous evidence for a locus predisposing to severe bipolar disorder at 5q31-33. Am J Med Genet B Neuropsychiatr Genet 125B:83-86.

Junghans D, Heidenreich M, Hack I, Taylor V, Frotscher M, Kemler R (2008) Postsynaptic and differential localization to neuronal subtypes of protocadherin beta16 in the mammalian central nervous system. Eur J Neurosci 27:559-571.

Kaneko R, Kato H, Kawamura Y, Esumi S, Hirayama T, Hirabayashi T, Yagi T (2006) Allelic gene regulation of Pcdh-alpha and Pcdh-gamma clusters involving both monoallelic and biallelic expression in single Purkinje cells. J Biol Chem 281:30551-30560.

Kawamoto S, Niwa H, Tashiro F, Sano S, Kondoh G, Takeda J, Tabayashi K, Miyazaki J (2000) A novel reporter mouse strain that expresses enhanced green fluorescent protein upon Cre-mediated recombination. FEBS Lett 470:263-268.

Kerner B, Brugman DL, Freimer NB (2007) Evidence of linkage to psychosis on chromosome 5q33-34 in pedigrees ascertained for bipolar disorder. Am J Med Genet B Neuropsychiatr Genet 144B:74-78.

Kohmura N, Senzaki K, Hamada S, Kai N, Yasuda R, Watanabe M, Ishii H, Yasuda M, Mishina M, Yagi T (1998) Diversity revealed by a novel family of cadherins expressed in neurons at a synaptic complex. Neuron 20:1137-1151.

Lewis CM, Levinson DF, Wise LH, DeLisi LE, Straub RE, Hovatta I, Williams NM, Schwab SG, Pulver AE, Faraone SV, Brzustowicz LM, Kaufmann CA, Garver DL, Gurling HM, Lindholm E, Coon H, Moises HW, Byerley W, Shaw SH, Mesen A, et al. (2003) Genome scan meta-analysis of schizophrenia and bipolar disorder, part II: schizophrenia. Am J Hum Genet 73:34-48.

Lidov HG, Molliver ME (1982) An immunohistochemical study of serotonin neuron development in the rat: ascending pathways and terminal fields. Brain Res Bull 8:389-430.

Lidov HG, Grzanna R, Molliver ME (1980) The serotonin innervation of the cerebral cortex in the rat-an immunohistochemical analysis. Neuroscience 5:207-227.

Lyons WE, Mamounas LA, Ricaurte GA, Coppola V, Reid SW, Bora SH, Wihler C, Koliatsos VE, Tessarollo L (1999) Brain-derived neurotrophic factor-deficient mice develop aggressiveness and hyperphagia in conjunction with brain serotonergic abnormalities. Proc Natl Acad Sci U S A 96:15239-15244.

Mamounas LA, Blue ME, Siuciak JA, Altar CA (1995) Brain-derived neurotrophic factor promotes the survival and sprouting of serotonergic axons in rat brain. J Neurosci 15:7929-7939.

Mamounas LA, Altar CA, Blue ME, Kaplan DR, Tessarollo L, Lyons WE (2000) BDNF promotes the regenerative sprouting, but not survival, of injured serotonergic axons in the adult rat brain. J Neurosci 20:771-782.

Mann JJ (1998) The role of in vivo neurotransmitter system imaging studies in understanding major depression. Biol Psychiatry 44:1077-1078.

Morishita H, Murata Y, Esumi S, Hamada S, Yagi T (2004) CNR/Pcdhalpha family in subplate neurons, and developing cortical connectivity. Neuroreport 15:2595-2599.

Morishita H, Umitsu M, Murata Y, Shibata N, Udaka K, Higuchi Y, Akutsu H, Yamaguchi T, Yagi T, Ikegami T (2006) Structure of the cadherinrelated neuronal receptor/protocadherin-alpha first extracellular cadherin domain reveals diversity across cadherin families. J Biol Chem 281:33650-33663.

Murata Y, Hamada S, Morishita H, Mutoh T, Yagi T (2004) Interaction with protocadherin-gamma regulates the cell surface expression of protocadherin-alpha. J Biol Chem 279:49508-49516.

Mutoh T, Hamada S, Senzaki K, Murata Y, Yagi T (2004) Cadherin-related neuronal receptor 1 (CNR1) has cell adhesion activity with betal integrin mediated through the RGD site of CNR1. Exp Cell Res 294:494-508.

Nishiyama H, Takemura M, Takeda T, Itohara S (2002) Normal development of serotonergic neurons in mice lacking S100B. Neurosci Lett 321:49-52.

Obata S, Sago H, Mori N, Rochelle JM, Seldin MF, Davidson M, St John T, Taketani S, Suzuki ST (1995) Protocadherin Pcdh2 shows properties similar to, but distinct from, those of classical cadherins. J Cell Sci 108:3765-3773

Pedrosa E, Stefanescu R, Margolis B, Petruolo O, Lo Y, Nolan K, Novak T, Stopkova P, Lachman HM (2008) Analysis of protocadherin alpha gene enhancer polymorphism in bipolar disorder and schizophrenia. Schizophr Res 102:210-219.

Phillips GR, Tanaka H, Frank M, Elste A, Fidler L, Benson DL, Colman DR (2003) Gamma-protocadherins are targeted to subsets of synapses and intracellular organelles in neurons. J Neurosci 23:5096-5104.

Schaeren-Wiemers N, Gerfin-Moser A (1993) A single protocol to detect transcripts of various types and expression levels in neural tissue and cultured cells: in situ hybridization using digoxigenin-labelled cRNA probes. Histochemistry 100:431-440.

Schwab SG, Eckstein GN, Hallmayer J, Lerer B, Albus M, Borrmann M, Lichtermann D, Ertl MA, Maier W, Wildenauer DB (1997) Evidence suggestive of a locus on chromosome $5 \mathrm{q} 31$ contributing to susceptibility for schizophrenia in German and Israeli families by multipoint affected sib-pair linkage analysis. Mol Psychiatry 2:156-160.

Sugino H, Hamada S, Yasuda R, Tuji A, Matsuda Y, Fujita M, Yagi T (2000) Genomic organization of the family of CNR cadherin genes in mice and humans. Genomics 63:75-87.

Triana-Baltzer GB, Blank M (2006) Cytoplasmic domain of protocadherinalpha enhances homophilic interactions and recognizes cytoskeletal elements. J Neurobiol 66:393-407.

Woolsey TA, Van der Loos H (1970) The structural organization of layer IV in the somatosensory region (SI) of mouse cerebral cortex. The description of a cortical field composed of discrete cytoarchitectonic units. Brain Res 17:205-242.

Wotherspoon G, López-Costa JJ, Michael GJ, Priestley JV (1997) Constitutive expression of calmodulin-binding phosphoprotein GAP-43 in rat serotonergic and noradrenergic cell groups which project to the spinal cord. Neurochem Res 22:985-993.

Wu Q, Maniatis T (1999) A striking organization of a large family of human neural cadherin-like cell adhesion genes. Cell 97:779-790.

Wu Q, Zhang T, Cheng JF, Kim Y, Grimwood J, Schmutz J, Dickson M, Noonan JP, Zhang MQ, Myers RM, Maniatis T (2001) Comparative DNA sequence analysis of mouse and human protocadherin gene clusters. Genome Res 11:389-404.

Yagi T (2008) Clustered protocadherin family. Dev Growth Differ 50 [Suppl 1]:S131-S140. 